\title{
Oxytocin prevents the increase of cocaine-related responses produced by social defeat
}

\author{
Carmen Ferrer-Pérez ${ }^{\mathrm{a}, 1}$, Adriana Castro-Zavala ${ }^{\mathrm{b}, 1}$, Miguel Ángel Luján ${ }^{\mathrm{b}}$, Joanna Filarowska ${ }^{\mathrm{c}}$, \\ Raúl Ballestín ${ }^{\mathrm{a}}$, José Miñarro ${ }^{\mathrm{a}}$, Olga Valverde ${ }^{\mathrm{b}}$, Marta Rodríguez-Arias ${ }^{\mathrm{a}, *}$ \\ ${ }^{a}$ Unit of Research on Psychobiology of Drug Dependence, Department of Psychobiology, Faculty of Psychology, Universitat de València, Valencia, Spain \\ ${ }^{\mathrm{b}}$ Neurobiology of Behavior Research Group (GReNeC-NeuroBio), Department of Health and Experimental Sciences, University Pompeu Fabra, IMIM (Hospital del Mar \\ Medical Research Institute), Barcelona, Spain \\ ${ }^{\mathrm{c}}$ Department of Pharmacology and Pharmacodynamics, Medical University of Lublin, Chodzki 4a, 20-093, Lublin, Poland
}

\section{H I G H L I G H T S}

- Social defeat stress induces a long-lasting increase in anxiety like behavior.

- Social defeat stress enhances rewarding properties of cocaine.

- Social defeat stress increase BDNF levels in prefrontal cortex.

- Oxytocin treatment favors the extinction of cocaine-associated memories.

- Oxytocin administration counteracts stress effect in anxiety and in BDNF levels.

\section{A R T I C L E I N F O}

\section{Keywords:}

Social defeat

Oxytocin

Cocaine

BDNF

Self-administration

Conditioned place preference

\begin{abstract}
A B S T R A C T
The neuropeptide oxytocin (OXT) plays a critical role in the regulation of social and emotional behaviors. OXT plays a role in stress response and in drug reward, but to date no studies have evaluated its implication in the long-lasting increase of the motivational effects of cocaine induced by repeated social defeat (RSD). During the social defeat procedure, $1 \mathrm{mg} / \mathrm{kg}$ of OXT was administered $30 \mathrm{~min}$ before each episode of RSD. Three weeks after the last defeat, the effects of cocaine on the conditioned place preference (CPP), locomotor sensitization and the self-administration (SA) paradigms were evaluated. The influence of OXT on the levels of BDNF in the prefrontal cortex (PFC), striatum and hippocampus was also measured. Our results confirm that raising the levels of OXT during social defeat stress can block the long-lasting effects of this type of stress. OXT counteracts the anxiety induced by social defeat and modifies BDNF levels in all the structures we have studied. Moreover, OXT prevents RSD-induced increases in the motivational effects of cocaine. Administration of OXT before each social defeat blocked the social defeat-induced increment in the conditioned rewarding effects of cocaine in the CPP, favored the extinction of cocaine-associated memories in both the CPP and SA, and decreased reinstatement of cocaineseeking behavior in the SA. In conclusion, the long-lasting effects of RSD are counteracted by administering OXT prior to stress, and changes in BDNF expression may underlie these protective effects.
\end{abstract}

\section{Introduction}

The neuropeptide oxytocin (OXT) plays a critical role in the regulation of social and emotional behaviors (Johnson and Young, 2017; Neumann and Slattery, 2016). OXT is a nine-amino acid cyclic neuropeptide synthesized mainly in the supraoptic and paraventricular nuclei
(PVN) of the hypothalamus. It innervates brain regions associated with stress and reward, such as the amygdala, septum, nucleus accumbens (NAc) and the bed nucleus of stria terminalis, where OXT receptors (OXTR) are expressed (see Gimpl and Fahrenholz, 2001). OXT also plays an important role in learning and memory processes related to the fear response, and OXT neurons are activated by a variety of stressful

\footnotetext{
${ }^{*}$ Corresponding author. Unidad de Investigación Psicobiología de las Drogodependencias, Departamento de Psicobiología, Facultad de Psicología, Universitat de València, Avda. Blasco Ibáñez, 21, 46010, Valencia, Spain.

E-mail address: marta.rodriguez@uv.es (M. Rodríguez-Arias).

${ }^{1}$ Both authors equally contributed to the paper.
} 
stimuli (Onaka et al., 2012).

Several studies suggest that OXT produces prosocial behaviors, facilitating approach activities by inhibiting systems involved in social anxiety and defense (Heinrichs and Domes, 2008; Neumann et al., 2000). Generally, experiments involving administration of OXT reveal anxiolytic effects in humans (Kirsch, 2005; Petrovic et al., 2008) and animals (Neumann and Slattery, 2016; Smith and Wang, 2014; Yoshida et al., 2009), though anxiogenic reactions have also been described (Eckstein et al., 2014; Grillon et al., 2013; Peters et al., 2014), fueling the hypothesis that variables such as dose and administration context modulate the effects of OXT. On the other hand, it is well established that the OXT system is implicated in the homeostatic response to stress. Animal studies have highlighted profound alterations of said system after chronic administration of cocaine or following its withdrawal (Georgiou et al., 2016). In addition, postmortem studies in humans suffering from depression have revealed higher levels of OXT immunoreactive neurons in the hypothalamus (Purba et al., 1996). Altogether, these results indicate that OXT is a contributing factor to the pathophysiology of mood and drug-related disorders.

Stress is one of the main risk factors for depression, anxiety or addiction (Logrip et al., 2012; Sinha et al., 2011). The close association between the brain systems involved in the response to drugs of abuse and stress suggests environmental stressors can cause long-term changes in the brain's reward system function, inducing relapses in drug-seeking and -taking. The social defeat (SD) paradigm is considered the most representative animal model for studying the consequences of social stress (Hammels et al., 2015). The agonistic encounter between conspecifics of the same specie models the subordinate vs. outsider relation in human interactions (Selten et al., 2013; Tornatzky and Miczek, 1993). Numerous reports have proved that SD increases both cocaine self-administration (SA) and cocaine-induced conditioned place preference (CPP). Increased acquisition, motivation and reinstatement to take cocaine have been repeatedly observed using SA paradigms (Boyson et al., 2014; Covington and Miczek, 2001; Covington et al., 2005; Han et al., 2017; Holly et al., 2016; Quadros and Miczek, 2009). CPP studies have painted a similar picture, with SD inducing short- and long-lasting increases in the conditioned rewarding effects of cocaine, increasing the time needed to extinguish the preference and susceptibility to reinstatement of said preference (Hymel et al., 2014; McLaughlin et al., 2006; Montagud-Romero et al., 2016a and b; Land et al., 2009; Reguilón et al., 2017; Rodriguez-Arias et al., 2016, 2017).

SD stress induces pronounced physiological and endocrine responses, such as elevated levels of corticosterone (Lumley et al., 2000; Meerlo et al., 2002; Montagud-Romero et al., 2016b; Rodríguez-Arias et al., 2017), and alterations in the levels of BDNF (Wang et al., 2018; $\mathrm{Xu}$ et al., 2018). SD stress induces prolonged BDNF expression in the ventral tegmental area (VTA) (Berton et al., 2006; Fanous et al., 2010; Krishnan et al., 2007), and an enhanced expression of proBDNF in the dentate gyrus (DG) and basolateral amygdala (BLA) in adult and adolescent mice subjected to SD (Montagud-Romero et al., 2017). The diverse intracellular signaling pathways activated by BDNF may underlie responses to drugs, stress, or mood disorders (Nikulina et al., 2014). For example, increased BDNF levels within the mesolimbic dopamine (DA) system are associated with the development of a depressive-like phenotype (Nestler and Carlezon, 2006), and current evidence strongly implicates BDNF-TrkB signaling in the response to clinically used antidepressant drugs (for review see Björkholm and Monteggia, 2016). In addition, alterations in mesocorticolimbic BDNF expression have been associated with the abuse potential of many drugs (Fumagalli et al., 2007; Le Foll et al., 2005; McGough, 2004; Meredith et al., 2002; Numan et al., 1998).

SD stress activates the PVN OXT neurons and OXTR -expressing neurons in various brain regions, facilitating SD posture during defeat stress (Nasanbuyan et al., 2018). Recent research suggests that OXT modulates the stress response via its action on the hypothalamic-pituitary-adrenal (HPA) axis (Lukas and Neumann, 2014; Parker et al.,
2005). The relation between OXT and SD on the other hand is not clear if current literature is consulted. Several studies indicate that SD does not alter OXT release (Engelmann et al., 1999; Wotjak et al., 1996). In line with this, Wang et al. (2018) observed that chronic SD reduced levels of OXT and OXTR in the shell region of the NAc. However, intraNAc shell OXT microinjections reversed alterations in social behavior induced by chronic SD, whereas injections of an OXTR antagonist blocked these effects. Other studies have demonstrated that OXT expression in the PVN is enhanced after single social defeat or acute emotional stress (Ebner et al., 2000; Engelmann et al., 1999), and defeated mice have been shown to display elevated levels of OXTR mRNA levels in the lateral septum (Litvin et al., 2011). A recent report has described stress-induced increases in the activation OXTR and produces social withdrawal, while a single dose of OXT - either systemically or within the bed nucleus of the stria terminalis - reverses this stress-induced social avoidance in female mice (Duque-Wilckens et al., 2018). These findings imply an until now unappreciated therapeutic potential of OXT in stress-induced psychiatric disorders.

In line with this, there is strong evidence that OXT is a promising therapeutic agent for the treatment of addiction disorders. It has been hypothesized that there is an association between the oxytocinergic and dopaminergic systems by which they regulate motivational behaviors (Zanos et al., 2014). Central or peripheral administration of OXT acutely increases DA utilization within the NAc, while chronic administration of OXT decreases DA utilization within the basal forebrain of mice (Kovàcs et al., 1986, 1990). In addition, there is strong evidence that OXT plays a role in the rewarding effects of drugs of abuse. Studies in humans show that cocaine use decreases plasma OXT levels (Light et al., 2004), and OXT administration decreases stress-induced craving for marijuana (McRae-Clark et al., 2013) and alcohol withdrawal symptoms (Pedersen et al., 2013). Equally, in basic studies, OXT has been shown to reduce ethanol SA in mice (King et al., 2017; MacFadyen et al., 2016) and morphine tolerance and withdrawal effects (Sarnyai and Kovács, 2014). With respect to psychostimulants, OXT blocks methamphetamine-conditioned behaviors (Qi et al., 2009) and reduces reinstatement of methamphetamine seeking (Baracz and Cornish, 2016; Carson et al., 2010; Cox et al., 2013). Both central and peripheral OXT administration attenuates cocaine-induced locomotor hyperactivity, stereotypies (Kovàcs et al., 1990; Sarnyai et al., 1990, 1991) and tolerance to stereotypies (Sarnyai et al., 1992). Systemic OXT decreases cocaine intake during SA, and prime or cue-induced reinstatement of cocaine seeking (Leong et al., 2016, 2017; Sarnyai and Kovács, 1994; Zhou et al., 2014).

Despite the clear role of OXT in the stress response and in the rewarding effects of drugs, no studies to date have evaluated its role in the long-lasting increase of the motivational effects of cocaine induced by repeated social defeat (RSD). To respond to this gap in the literature, we administered $1 \mathrm{mg} / \mathrm{kg}$ of OXT $30 \mathrm{~min}$ before each episode of SD and three weeks after the last defeat, we evaluated the motivational effects of cocaine in different paradigms, including the CPP, the locomotor sensitization and the SA. Due to the pivotal role of BDNF in SD stress, we have also evaluated the effect of OXT on the levels of this neurotrophin in the prefrontal cortex (PFC), striatum (STR) and hippocampus (HIP) in socially defeated mice.

\section{Material and methods}

\subsection{Animals}

A total number of 240 OF1 adult mice (Charles River, France) were used in this study. Experimental mice were housed in groups of four in plastic cages $(27 \times 27 \times 14 \mathrm{~cm})$ during the entire experimental procedure. Aggressive opponents were individually housed in plastic cages $(21 \times 32 \times 20 \mathrm{~cm})$ for at least a month prior to the initiation of the experiments in order to heighten aggression (Rodríguez-Arias et al., 1998). All mice were housed under the following conditions: constant 
temperature; a reversed light schedule (white light on 8:00-20:00 h); and food and water available ad libitum, except during behavioral tests. All procedures were conducted in compliance with the guidelines of the European Council Directive 2010/63/UE regulating animal research and were approved by the local ethics committees of the University of Valencia and the UPF/PRBB respectively.

\subsection{Drugs}

For pre-treatment Oxytocin (Sigma-Aldrich, Spain) was dissolved in physiological saline ( $\mathrm{NaCl} 0.9 \%)$ and injected intraperitoneally (i.p.) at a dose of $1 \mathrm{mg} / \mathrm{kg} 30 \mathrm{~min}$ before each social defeat episode. For CPP establishment, doses of $1 \mathrm{mg} / \mathrm{kg}$ and $10 \mathrm{mg} / \mathrm{kg}$ of cocaine hydrochloride (Alcaliber laboratory, Spain) were used. These doses of cocaine were selected on the basis of previous CPP studies showing $1 \mathrm{mg} / \mathrm{kg}$ to be a non-effective dose and $10 \mathrm{mg} / \mathrm{kg}$ to be an effective dose (Arenas et al., 2014; Montagud-Romero et al., 2014; Vidal-Infer et al., 2012). For SA studies a non-effective dose of $0.5 \mathrm{mg} / \mathrm{kg} /$ infusion of cocaine was used for the acquisition phase and a priming injection of $10 \mathrm{mg} / \mathrm{kg}$, i.p. to induce reinstatement. All i.p. administrations were adjusted in a volume of $0.01 \mathrm{ml} / \mathrm{g}$ of body weight. Saline control groups (SAL) were injected with physiological saline ( $\mathrm{NaCl} 0.9 \%)$, which was also used to dissolve cocaine.

\subsection{Experimental design}

The experimental design is depicted in Table 1.

Table 1. The first set of mice (CPP experiment) was composed of a total of 96 animals that underwent an RSD/EXP protocol and whose anxiety-like behavior was assessed three weeks later using the EPM. Subsequently, the animals underwent CPP induced by $1 \mathrm{mg} / \mathrm{kg}$ ( $\mathrm{n}=45)$ or $10 \mathrm{mg} / \mathrm{kg}$ cocaine $(\mathrm{n}=51)$. Finally, 10 days after extinction of the CPP induced by $1 \mathrm{mg} / \mathrm{kg}$ of cocaine, the locomotor sensitization protocol was performed.

The second set of mice (SA experiment) was composed of a total of 92 animals that underwent an RSD/EXP protocol. After 12-16 days, the animals underwent surgery to implant a catheter for the cocaine SA procedure. After three days of post-surgery recovery the SA protocol took place.

The third set of mice (Brain samples) was composed of 20 animals that underwent an RSD/EXP protocol and were sacrificed for brain sampling three weeks later.

\subsection{Apparatus and procedures}

\subsubsection{Procedure of social defeat}

Each episode of SD consisted of three phases, which began by introducing the "intruder" (the experimental animal) into the home cage of the "resident" (the aggressive opponent) for $10 \mathrm{~min}$ (Tornatzky and Miczek, 1993). During this initial phase, the intruder was protected from attack, but the wire mesh walls of the cage allowed for social interaction and species-typical threats from the male aggressive resident, thus leading to instigation and provocation (Covington and Miczek, 2001). The wire mesh was then removed from the cage to allow confrontation between the two animals for a 5-min period. In the third phase, the wire mesh was returned to the cage to separate the two animals once again for another $10 \mathrm{~min}$ to allow for social threats by the resident. Intruder mice were exposed to a different aggressor mouse during each episode of SD. The criterion used to define an animal as defeated was the adoption of a specific posture signifying defeat, characterized by an upright submissive position, limp forepaws, upwardly angled head, and retracted ears (Miczek et al., 1982; RodríguezArias et al., 1998). All agonistic encounters were videotaped to confirm social defeat of the intruder mice and to perform an ethological analysis of the attack behaviors (duration) of the resident mice. The exploration groups followed the same protocol, but without the presence of "resident" mice: the mouse was placed in a new cage enclosed with a wire mesh for $10 \mathrm{~min}$, after which the mesh was removed for $5 \mathrm{~min}$ and then returned again for the 10 last minutes of each exploration session.

\subsubsection{Elevated plus maze-EPM}

The elevated plus maze (EPM) test was carried out essentially following the procedure described by Daza-Losada and cols. (2009). The maze consisted of two open arms $(30 \times 5 \times 0.25 \mathrm{~cm})$ and two enclosed arms $(30 \times 5 \times 15 \mathrm{~cm})$, and the junction of the four arms formed a central platform $(5 \times 5 \mathrm{~cm})$. The floor of the maze was made of black Plexiglas and the walls of the enclosed arms were made of clear Plexiglas. The open arms had a small edge $(0.25 \mathrm{~cm})$ to provide the animals with additional grip. The entire apparatus was elevated $45 \mathrm{~cm}$ above floor level. In order to facilitate adaptation, mice were transported to the dimly illuminated laboratory $1 \mathrm{~h}$ prior to testing. At the beginning of each trial, subjects were placed on the central platform so that they were facing an open arm and were allowed to explore for $5 \mathrm{~min}$. The maze was thoroughly cleaned with a damp cloth after each trial. The measurements recorded during the test period were number of entries and time and percentage of time spent in each section of the apparatus (open arms, closed arms, central platform). An arm was considered to have been visited when the animal placed all four paws on it. The time and percentage of time spent in the open arms and the number of open arm entries are generally used to characterize the anxiolytic effects of drugs. In addition, the number of closed and total entries indicates motor activity.

\subsubsection{Conditioned place preference-CPP}

Place conditioning consisted of three phases and took place during the dark cycle (Maldonado et al., 2006), following an unbiased procedure in initial spontaneous preference terms (for a detailed explanation of the procedure (see Daza-Losada et al., 2009). For place conditioning, twelve identical Plexiglas boxes with a black and white equally sized compartments $(30.7 \mathrm{~cm} \times 31.5 \mathrm{~cm} \times 34.5 \mathrm{~cm})$ separated by a grey

Table 1

Experimental design.

\begin{tabular}{|c|c|c|c|c|c|c|c|c|c|c|c|}
\hline \multirow[t]{3}{*}{ 1st set of mice CPP } & & \multicolumn{6}{|c|}{ Social defeat / Exploration } & \multicolumn{3}{|c|}{ CPP ( 1 or $10 \mathrm{mg} / \mathrm{kg}$ cocaine) } & \multirow{3}{*}{$\begin{array}{l}\text { Locomotor } \\
\text { sensitization } \\
\text { Induction Test } \\
>94\end{array}$} \\
\hline & & 1 st & 2nd & 3 rd & 4th & 3 weeks & EPM & Pre-C test & Conditioning & Post-C test & \\
\hline & PND & 47 & 50 & 53 & 56 & & 76 & 77-78-79 & $80-83$ & & \\
\hline \multirow{3}{*}{ 2nd set of mice SA } & & \multicolumn{4}{|c|}{ Social defeat / Exploration } & & Catheter & \multicolumn{2}{|c|}{ Cocaine self-administration } & & \\
\hline & & 1st & 2nd & 3 rd & 4th & & implantation & $\begin{array}{l}\text { Acquisition } \\
\text { phase }\end{array}$ & Extinction phase & Reinstatement & \\
\hline & PND & 47 & 50 & 53 & 56 & & $68-72$ & $77-88$ & $89-114$ & 117 & \\
\hline \multirow{3}{*}{$\begin{array}{l}\text { 3rd set of mice } \\
\text { Brain samples }\end{array}$} & & \multicolumn{4}{|c|}{ Social defeat / Exploration } & & & & & & \\
\hline & & 1 st & 2nd & 3rd & 4th & & Brain Samples & & & & \\
\hline & PND & 47 & 50 & 53 & 56 & & 77 & & & & \\
\hline
\end{tabular}


central area $(13.8 \mathrm{~cm} \times 31.5 \mathrm{~cm} \times 34.5 \mathrm{~cm})$ and containing photoelectric cells were used (Cibertec, S.A., Madrid, Spain). In brief, during preconditioning (Pre-C), the time spent by the animal in each compartment over a 15-min period was recorded. Mice showing a strong unconditioned aversion (less than $33 \%$ of the time spent in either compartments) or preference (more than 67\%) for any compartment were excluded from the study.

In the second phase (conditioning), animals underwent two pairings per day. First, they received an injection of physiological saline before being confined to the vehicle-paired compartment for $30 \mathrm{~min}$. After a 4$\mathrm{h}$ interval, they received cocaine immediately before being confined to the drug-paired compartment for $30 \mathrm{~min}$. In the third phase or postconditioning (Post-C), the time spent by the untreated mice in each compartment during a 15-min observation period was recorded. The difference in seconds between the time spent in the drug-paired compartment in the Post- $C$ test and that spent in the Pre- $C$ test is a measure of the degree of conditioning induced by the drug. If this difference is positive, then the drug is considered to have induced a preference for the drug-paired compartment, whereas the opposite indicates induction of an aversion.

All groups in which a preference for the drug-paired compartment was established underwent an extinction session every $72 \mathrm{~h}$, which consisted of placing mice in the apparatus for $15 \mathrm{~min}$. This was repeated until the time spent in the drug-paired compartment by each group was similar to that of Pre-C.

The effects of non-contingent administration of a priming dose of cocaine were evaluated $24 \mathrm{~h}$ after confirmation of extinction. Reinstatement tests were the same as for Post-C (free ambulation for $15 \mathrm{~min}$ ), except that mice were tested $15 \mathrm{~min}$ after administration of the drug (half of the dose used for conditioning). After this first reinstatement test, the groups that demonstrated reinstatement-i.e. a positive significant difference between the time spent in the drug-paired compartment in the reinstatement and last extinction tests-were retested until a new extinction was confirmed. The following day, the effects of the priming (a quarter of the dose used for conditioning) on reinstatement of place preference were evaluated following the procedure described previously. This procedure was repeated with progressively lower priming doses until a non-effective priming injection was determined.

\subsubsection{Locomotor sensitization testing}

Locomotor sensitization induced by cocaine was measured by evaluating the movements of mice inside the cage by means of photocell beam breaks. Ten days after extinction of the CPP in the group of animals conditioned with $1 \mathrm{mg} / \mathrm{kg}$ cocaine, mice were assigned to a cocaine or saline condition and injected with a dose of $25 \mathrm{mg} / \mathrm{kg}$ per day of either on three consecutive days in their home cages. After five days with no treatment all mice were injected with $10 \mathrm{mg} / \mathrm{kg}$ cocaine and placed for the first time in the actimeter. Locomotor activity was automatically measured by an actimeter (Cibertec S.A., Madrid, Spain) consisting of eight cages $(33 \times 15 \times 13 \mathrm{~cm})$, each with eight infrared lights located in a frame around the cage. In this apparatus, beams are positioned on the horizontal axis $2 \mathrm{~cm}$ apart, at a height just above the bottom of the cage (body level of mice). The different frames are placed $4 \mathrm{~cm}$ apart and, since they are opaque, prevent animals from seeing each other while allowing them to hear and smell conspecifics being tested at the same time.

\subsubsection{Operant cocaine self-administration}

The SA experiments were carried out in mouse operant chambers (Model ENV-307A-CT, Medical Associates, Cibertec S.A., Madrid, Spain) containing two holes; one was defined as active and the other as inactive. Nose-poking in the active hole produced a cocaine infusion that was paired with two light stimuli, one placed inside the nose-poke and the other above the active hole. Nose-poking in the inactive hole had no consequences. The side on which active/inactive holes were placed were counterbalanced. The chambers were placed in sound- and light-attenuated boxes retrofitted with fans to provide ventilation and white noise.

Surgery for catheter implantation. The surgery to implant the intravenous catheter was performed as described previously (Soria et al., 2008; López-Arnau et al., 2017). Surgery was carried out in 24 animals in the exploration/saline group (EXP-SAL), 25 animals in the repeated social defeat/saline group (RSD-SAL), 19 animals in the exploration/ oxytocin group (EXP-OXT), and 24 in the repeated social defeat/oxytocin group (RSD-OXT). In short, mice were anaesthetized with a mixture of ketamine/xylazine $(50 \mathrm{mg} / \mathrm{ml}, 10 \mathrm{mg} / \mathrm{ml}$, administrated in a volume of $0.15 \mathrm{ml} / 10 \mathrm{~g}$ ) and then implanted with a jugular catheter. Animals were treated with analgesic (meloxicam $0.5 \mathrm{mg} / \mathrm{kg}$; i.p., administrated in a volume of $0.10 \mathrm{ml} / 10 \mathrm{~g}$ body weight) and antibiotic solution (Enrofloxacin $7.5 \mathrm{mg} / \mathrm{kg}$; i.p., administrated in a volume of $0.03 \mathrm{ml} / 10 \mathrm{~g}$ body weight). After surgery, animals were housed individually, placed over electric blankets, and allowed to recover.

2.4.5.1. Acquisition. At least 3 days after surgery, animals were trained (on a fixed ratio 1, FR1) to self-administer cocaine $(0.5 \mathrm{mg} / \mathrm{kg}$ per infusion) during 10 daily sessions $(2 \mathrm{~h})$. Cocaine infusion of $20 \mu \mathrm{l}$ was delivered over $2 \mathrm{~s}$ via a syringe collocated on a microinfusion pump (PHM-100A, Med-Associates, Georgia, VT, USA), connected via Tygon tubing $(0.96 \mathrm{~mm}$ outer diameter, Portex Fine Bore Polythene Tubing, Portex Limited, Kent, England) to a liquid swivel (375/25, Instech Laboratories, Plymouth Meeting, PA, USA) and the intravenous catheter. In order to avoid overdosing, mice received a maximum of 150 infusions, and each infusion was followed by a 15-s time-out period in which no cocaine infusions were delivered. At the beginning of each session, the house light was $\mathrm{ON}$ for $3 \mathrm{~s}$ and OFF during the rest of the experiment. The session started with a priming injection of cocaine and a 4-s light cue situated above the active hole. The number of infusions (responses during time in) in the active and the inactive hole were counted. The criteria for the acquisition of a stable SA were: 5 or more responses in the active hole; more than $65 \%$ of responses in the active hole; and a stable response with less than $30 \%$ deviation from the mean of the total number of cocaine infusions obtained on two consecutive days $(70 \%$ of stability).

2.4.5.2. Extinction. Only animals that fulfilled the acquisition criteria underwent the extinction phase. In this phase, the experimental conditions were the same as those in the acquisition phase, except that the active hole produced no consequences and the stimulus light was turned off. The number of extinction sessions varied depending on each animal. The number of responses (during time in) in the active and the inactive holes were counted. The extinction criteria were: less than $30 \%$ of active responses on the day of maximum consumption during the acquisition phase, and a stable response with less than $30 \%$ deviation from the mean of the total number of responses obtained on two consecutive days (70\% of stability).

The patency of the intravenous catheters was evaluated at the end of the first extinction session by infusion of $0.1 \mathrm{ml}$ of tiobarbital (thiopental sodium; $5 \mathrm{mg} / \mathrm{ml}$; i.v.; B. Braun Medical, S.A. Rubí, Barcelona, Spain). If signs of anesthesia did not appear within the first $3 \mathrm{~s}$, the mouse was removed from the experiment.

2.4.5.3. Reinstatement. Only animals who fulfilled the extinction criteria were subjected to the reinstatement phase. The day after mouse met said criteria, reinstatement was induced by a priming injection of cocaine $(10 \mathrm{mg} / \mathrm{kg}$; i.p.). Immediately following cocaine administration, the mouse was placed in the self-administration box to initiate the reinstatement procedure. The number of responses (during time in) in the active- and the inactive hole were counted. The reinstatement session was identical to the acquisition sessions, only that animals did not receive the drug infusions. 


\subsubsection{Sample collection and BDNF quantification}

Five animals per group - exploration/saline (EXP-SAL), repeated social defeat/saline (RSD-SAL), exploration/oxytocin (EXP-OXT) and repeated social defeat/oxytocin (RSD-OXT) groups - were sacrificed by cervical dislocation. The brains were immediately removed from the skull and placed on a cold plaque. Cerebellum and olfactory bulbs were eliminated, and the different brain areas of interest were dissected (medial PFC, STR and HIP). Brain tissues samples were stored immediately at $-80^{\circ} \mathrm{C}$ until the BDNF assay was performed. Samples were homogenized in cold lysis buffer $(\mathrm{NaCl} 0.15 \mathrm{M}$, EDTA $0.001 \mathrm{M}$, Tris pH 7.4 0.05 M, TX-100 1\%, Glycerol 10\%) supplemented with protease inhibitor (Complete ULTRA Tablets Mini EASYpack, Roche, Mannheim, Germany) and phosphatase inhibitor (PhosSTOP EASYpack, Roche, Mannheim, Germany). For BDNF quantification, the sandwichstyle ELISA using the Emax ImmunoAssay System (Promega, Madrid, Spain) was performed according to the manufacturer's instructions. The protein concentration of each sample was evaluated using the DC Protein Assay (Biorad, Madrid, Spain) to determine the number of picograms of BDNF per $100 \mathrm{mg}$ of protein.

\subsection{Statistical analyses}

For the CPP induced by $1 \mathrm{mg} / \mathrm{kg}$ of cocaine, the time spent in the drug-paired compartment was analyzed using an ANOVA with a between-subjects variable - Treatment, with four levels (SAL-EXP, SALRSD, OXT-EXP and OXT-RSD)—and a within-subjects variable-Days, with two levels (Pre-C and Post-C). For the $10 \mathrm{mg} / \mathrm{kg}$ cocaine CPP, the data was analyzed with a three-way ANOVA with two between-subjects variables - Treatment, with two levels (SAL and OXT) - and Stress, with two levels (RSD and EXP) and a within-subjects variable-Days, with two levels (Pre-C and Post-C). In the groups showing CPP, extinction and reinstatement values were analyzed by a Student's t-test. The time required for the preference to be extinguished in each animal was analyzed by means of the Kaplan-Meier test with Breslow (generalized Wilcoxon) comparisons when appropriate (Daza-Losada et al., 2009). Although the mean of the group as a whole determined the day on which extinction was considered to have been achieved, preference was considered to be extinguished when a mouse spent $380 \mathrm{~s}$ or less in the drug-paired compartment on two consecutive days. We chose this time based on the values of all the Pre-C tests performed in the study (mean $=370 \mathrm{~s}$ ). When the preference was not extinguished in an animal, it was assigned the number of days required for extinction for the group as a whole.

Data from the locomotor sensitization test were analyzed using a two-way ANOVA with two between-subjects variables - Treatment with four levels (SAL-EXP, SAL-RSD, OXT-EXP and OXT-RSD) - and Induction-treatment, with two levels (Saline and Cocaine). For the analysis of the EPM data a one-way ANOVA with a between-subjects variable- Treatment, with four levels (SAL-EXP, SAL-RSD, OXT-EXP and OXT-RSD) was performed. For the analysis of the data of intruder and resident behavior during social defeat a one-way ANOVA with a between-subjects variable - Treatment, with two levels (SAL-RSD and OXT-RSD) - was performed. In all cases, subsequent post-hoc comparisons were performed using the Bonferroni test. Data from the BDNF levels were analyzed using a two-way ANOVA with Treatment and Stress as independent factors, and the concentration of BDNF as the dependent variable.

Data from the acquisition of cocaine SA were analyzed using a fourway ANOVA with Treatment (SAL and OXT) and Stress (RSD and EXP) as between-subjects variables and Hole (Active or Inactive) and Days as within-subjects variables. For the extinction and reinstatement phases, we compared the responses obtained on the first extinction day, last extinction day and day of reinstatement. For this comparison, a fourway ANOVA was calculated using the same variables. For the result of total cocaine intake during acquisition, the day of acquisition and the day of extinction, two-way ANOVAs were calculated using the variables
Treatment and Stress. For the analysis of the percentages of acquisition, extinction and reinstatement respectively, chi-squared tests were calculated. Subsequent post-hoc analyses were performed when they corresponded using the Bonferroni test.

All statistical analyses were performed using SPSS Statistics v23. Data were expressed as mean \pm SEM and a value of $p<0.05$ was considered statistically significant.

\section{Results}

3.1. Oxytocin does not decrease the behavioral response of resident mice during social defeat

The ANOVA performed for the intruder mice's behavior data during the first episode of social defeat did not reveal any significant effects. In contrast, the analysis of the fourth social defeat revealed an effect of the variable Treatment $[F(2,13)=4.626 ; p=0.03]$, and the post-hoc analysis showed that oxytocin-treated mice spent less time in avoidance behavior $(\mathrm{p}=0.007)$ than animals injected with saline.

With respect to the behavior of resident mice, the ANOVA of the first defeat data did not reveal any significant effect of the variable Treatment, while the analysis of the fourth social defeat did show such an effect $[F(2,13)=14.525 ; p<0.001]$. Post-hoc analysis revealed that resident mice confronted with animals pretreated with oxytocin spent more time engaged in threat behavior $(p<0.001)$ but had a tendency to spend less time in attack $(p=0.061)$ (See Table 2).

Table 2. Oxytocin does not decrease the behavioral response of resident mice during social defeat $(n=8)$. Data are presented as mean of time in seconds (s). \pm S.E.M. Bonferroni test **p $<0.01$; $* * * \mathrm{p}<0.001$ significant difference with respect to the corresponding saline group.

\subsection{Oxytocin prevents the long-term anxiogenic effects of repeated social defeat}

The data of the EPM test are presented in Table 3. The ANOVA of the time spent in the open arms $[\mathrm{F}(3,52)=8.126$; $\mathrm{p}<0.01]$; percentage of time spent in the open arms $[\mathrm{F}(3,52)=6.553 ; \mathrm{p}<0.001]$; percentage of entries into the open arms $[(3,52)=2.782 ; \mathrm{p}=0.05]$; number of entries into the closed arms $[(3,52)=9.158 ; \mathrm{p}<0.01]$ revealed a significant effect of the variable Treatment. Post-hoc analyses showed that socially defeated animals pretreated with saline spent less time and a lower percentage of time in the open arms than animals in any of the exploration groups $(\mathrm{p}<0.001)$, and socially defeated animals pretreated with OXT ( $\mathrm{p}<0.05$ ). A lower percentage of entries into the open arms was registered in socially defeated animals pretreated with saline compared with defeated animals pretreated with oxytocin $(\mathrm{p}<0.05)$. On the other hand, socially defeated animals under saline treatment performed a higher number of entries into the closed arms than the rest of the groups ( $p<0.001)$.

Table 3. Administration of oxytocin before each social defeat prevents the long-lasting anxiogenic effect in the EPM (SAL-EXP $n=15$; SAL-RSD $\mathrm{n}=15$; OXT-EXP $\mathrm{n}=14$; OXT-RSD $\mathrm{n}=12$ ). Data are

Table 2

Behavior of resident and intruder mice during 5-min agonistic encounters.

\begin{tabular}{|c|c|c|c|c|}
\hline \multirow[t]{2}{*}{ Social Defeat } & \multicolumn{2}{|c|}{ Saline treated } & \multicolumn{2}{|c|}{ Oxytocin treated } \\
\hline & $1 \mathrm{st}$ & 4 st & $1 \mathrm{st}$ & 4th \\
\hline \multicolumn{5}{|c|}{ Intruder mice } \\
\hline Avoidance (s) & $16 \pm 3$ & $25 \pm 3$ & $15 \pm 5$ & $10 \pm 2 * *$ \\
\hline Defense/Submission (s) & $58 \pm 10$ & $74 \pm 12$ & $68 \pm 8$ & $51 \pm 14$ \\
\hline \multicolumn{5}{|c|}{ Resident mice } \\
\hline Threat (s) & $9 \pm 3$ & $5 \pm 2$ & $9 \pm 3$ & $16 \pm 2 * * *$ \\
\hline Attack (s) & $29 \pm 6$ & $28 \pm 5$ & $26 \pm 7$ & $15 \pm 4$ \\
\hline
\end{tabular}


Table 3

Long term effects of RSD on anxiety like behavior.

\begin{tabular}{lllll}
\hline & SAL-EXP & SAL-RSD & OXT-EXP & OXT-RSD \\
\hline Time in OA & $89 \pm 8$ & $42 \pm 5^{* * *}+$ & $61 \pm 2$ & $68 \pm 9$ \\
\%Time OA & $34 \pm 3$ & $17 \pm 2^{* * *}+$ & $33 \pm 1$ & $28 \pm 4$ \\
\%Entries OA & $35 \pm 3$ & $25 \pm 5+$ & $37 \pm 1$ & $42 \pm 4$ \\
Closed entries & $37 \pm 7$ & $81 \pm 13^{* * *}+++$ & $31 \pm 2$ & $32 \pm 4$ \\
\hline
\end{tabular}

presented as mean values of time in seconds (s). \pm S.E.M. Bonferroni test $* * * \mathrm{p}<0.001$ significant difference from non-stressed control groups (SAL-EXP and OXT-EXP) $+\mathrm{p}<0.05,+++\mathrm{p}<0.0001$ significant difference with respect to RSD animals treated with OXT (OXT-RSD).

\subsection{Oxytocin modifies the expression of BDNF in the prefrontal cortex, striatum and hippocampus of treated mice}

A two-way ANOVA of BDNF levels in the PFC revealed an effect of the variable Treatment $[\mathrm{F}(1,20)=9.006 ; \mathrm{p}<0.01]$ and the interaction between Treatment and Stress $[\mathrm{F}(1,20)=8.063$; $\mathrm{p}<0.05]$ (see Fig. 1A). A Bonferroni post-hoc test revealed a lower expression of BDNF in RSD-OXT vs. RSD-SAL mice ( $\mathrm{p}<0.01)$. In STR, a two-way ANOVA showed an effect of Treatment $[F(1,20)=13.647 ; p<0.01]$ and Stress $[\mathrm{F}(1,20)=8.639 ; \mathrm{p}<0.01]$, but no significant interaction between the two factors (see Fig. 1B). The effect of Treatment observed demonstrates that animals who received OXT expressed higher BDNF levels than those treated with saline in this brain area. The Stress effect reveals higher levels of BDNF in the STR in animals that experienced RSD vs. EXP. In the HIP, two-way ANOVA of BDNF levels indicated an effect of Treatment $[F(1,21)=20.647 ; p<0.001]$, Stress $[F$ $(1,21)=8.281 ; \mathrm{p}<0.01]$ and the interaction between these factors $[\mathrm{F}$

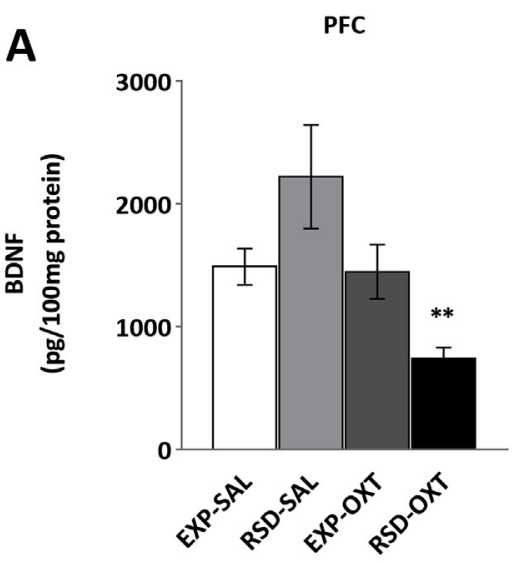

$(1,21)=5.702 ; p<0.05$ ] (see Fig. 1C). The post-hoc analysis shows that the levels of BDNF were higher in the RSD-OXT group compared with the EXP-SAL $(\mathrm{p}<0.001)$; RSD-SAL $(\mathrm{p}<0.001)$ and EXP-OXT groups $(\mathrm{p}<0.01)$, respectively.

3.4. Oxytocin blocks the increase in the conditioned rewarding effects of a subthreshold dose of cocaine $(1 \mathrm{mg} / \mathrm{kg})$ induced by social defeat stress

The ANOVA of the CPP data (see Fig. 2) showed a significant effect of the interaction Days and Treatment $[F(3,50)=3.930 ; p=0.014]$. As expected, socially defeated animals pretreated with saline (SAL-RSD) developed CPP, since they spent more time in the drug-paired compartment in the Post-C than in the Pre-C test $(\mathrm{p}<0.001)$. This place preference was not developed in defeated mice pre-treated with oxytocin (OXT-RSD).

3.5. Oxytocin decreases the number of sessions required to extinguish the place preference induced by $10 \mathrm{mg} / \mathrm{kg}$ cocaine in both stressed and nonstressed animals

The ANOVA of the CPP induced by $10 \mathrm{mg} / \mathrm{kg}$ of cocaine (see Fig. 3) showed a significant effect of the variable Days $[\mathrm{F}(1,47)=50.898$; $\mathrm{p}<0.001]$. Post-hoc comparisons showed that all groups developed a significant preference for the drug-paired compartment after being conditioned with $10 \mathrm{mg} / \mathrm{kg}$ of cocaine.

All groups were subjected to CPP extinction sessions, and the Kaplan-Meier analysis revealed that more time was required to achieve extinction in the SAL-RSD (17 sessions) than in those treated with oxytocin OXT-RSD $(\chi 2=6.667 ; \mathrm{p}=0.01)$ (9 sessions) or OXT-EXP ( $\chi 2=6.418 ; p=0.011$ ) (9 sessions) (see Fig. 4). Reinstatement of the preference after a priming dose of $5 \mathrm{mg} / \mathrm{kg}$ of cocaine was achieved in both saline groups - SAL-EXP and SAL-RSD ( $<<0.05)$ - and in socially
Fig. 1. Effects of RSD and/or OXT treatment on BDNF levels. Mean of BDNF levels (pg/100 mg protein) in (A) PFC, (B) STR and (C) HIP. Two-way ANOVA and subsequent Bonferroni post-hoc test. $\star \star \mathrm{p}<0.01$, versus EXP-OXT group. ${ }^{* \star \mathrm{p}}<0.01$, $* * * \mathrm{p}<0.001$, versus RSD-SAL group. $+\mathrm{p}<0.001$ versus EXP-SAL group. Data are expressed as mean of BDNF (pg/100 mg protein) \pm S.E.M. $(n=5)$.

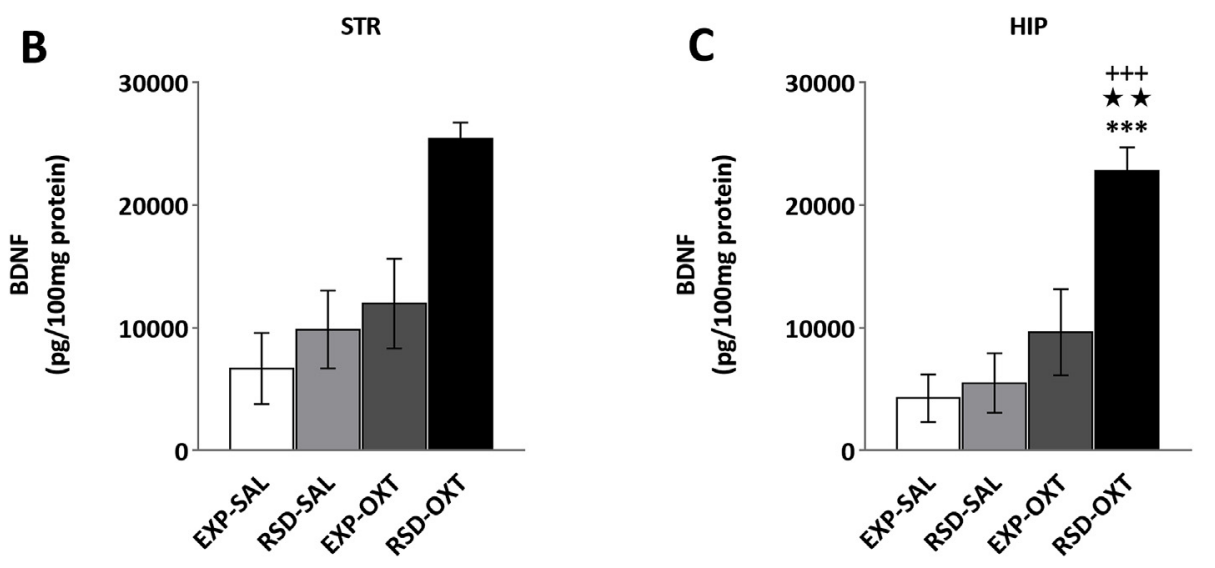




\section{CPP induced by $1 \mathrm{mg} / \mathrm{kg}$ cocaine}

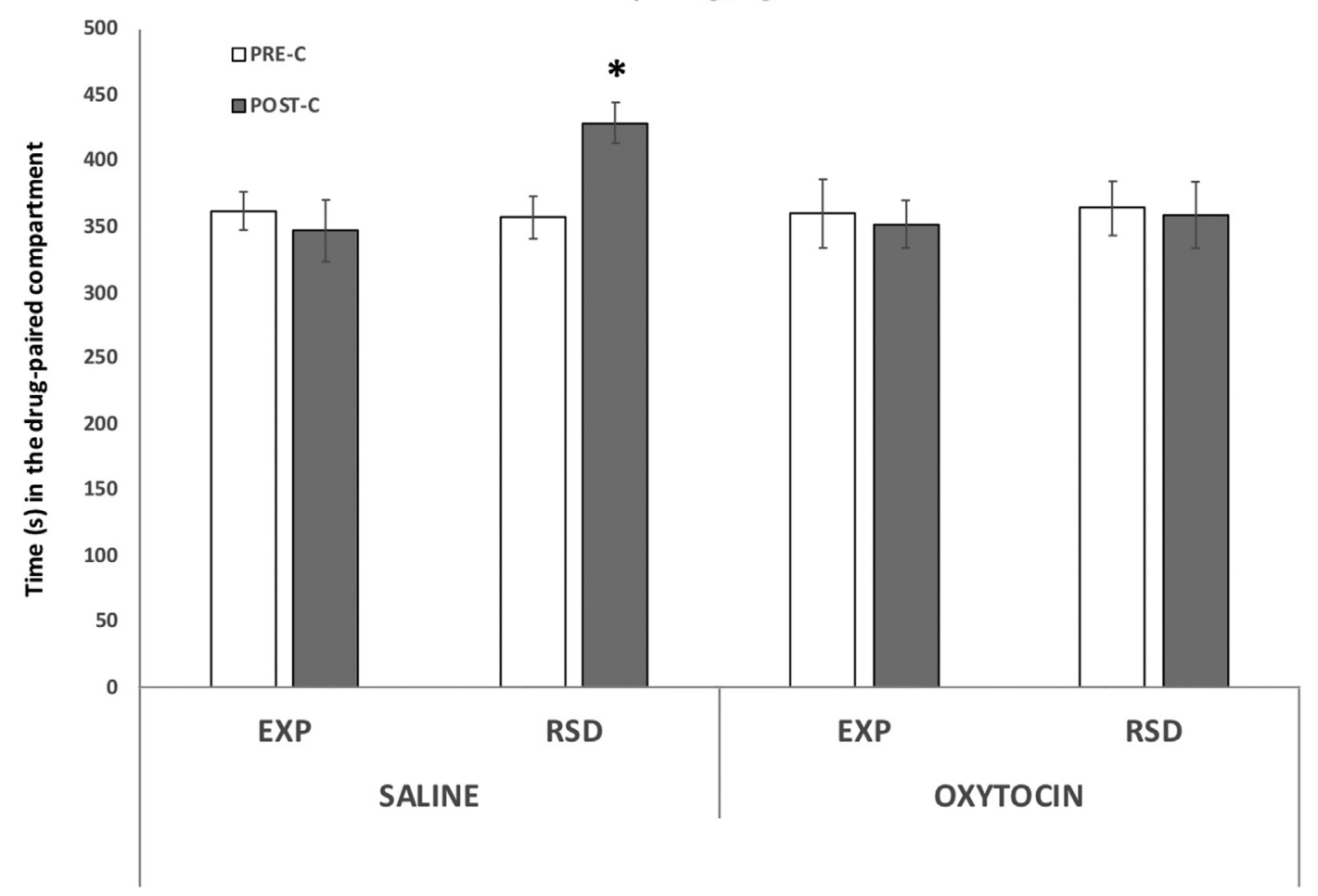

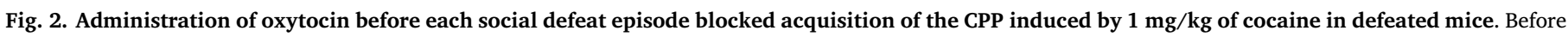

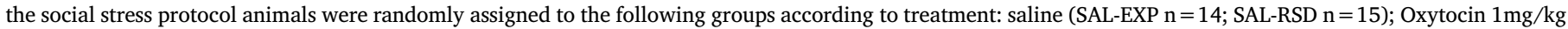

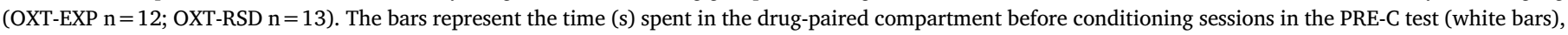

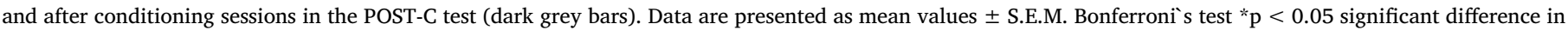
the time spent in the drug-paired compartment versus PRE-C.

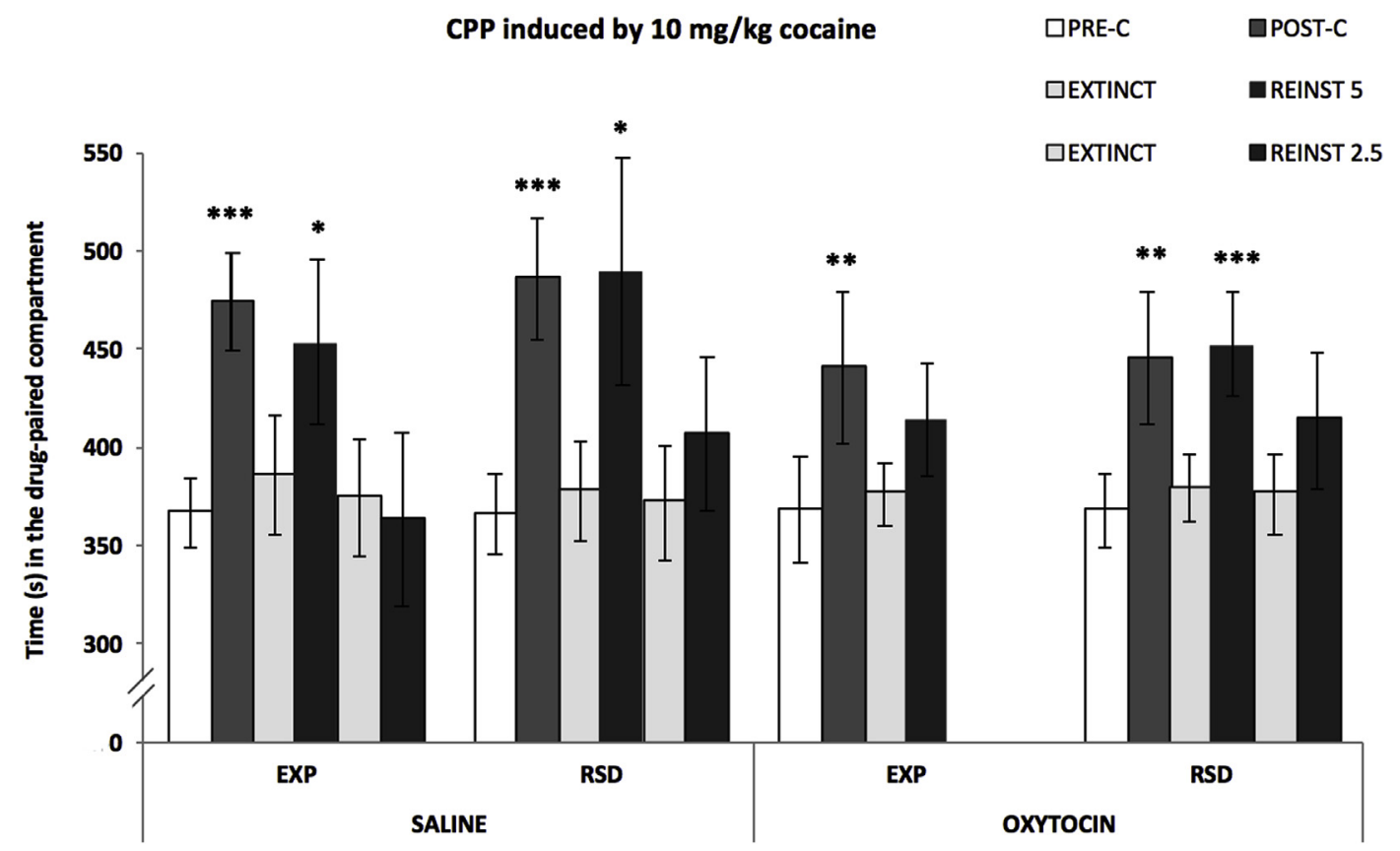

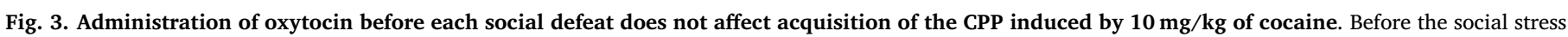

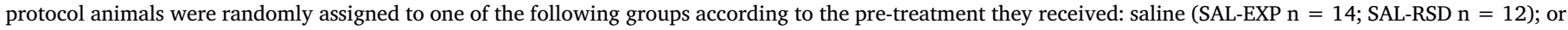

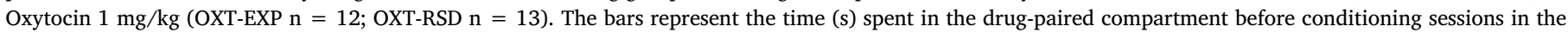

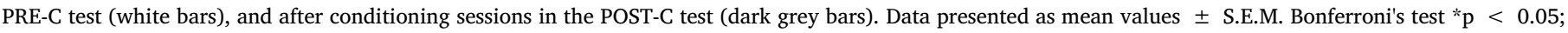
$* * \mathrm{p}<0.01 ; * * * \mathrm{p}<0.001$ significant difference in the time spent in the drug-paired compartment versus PRE-C. 


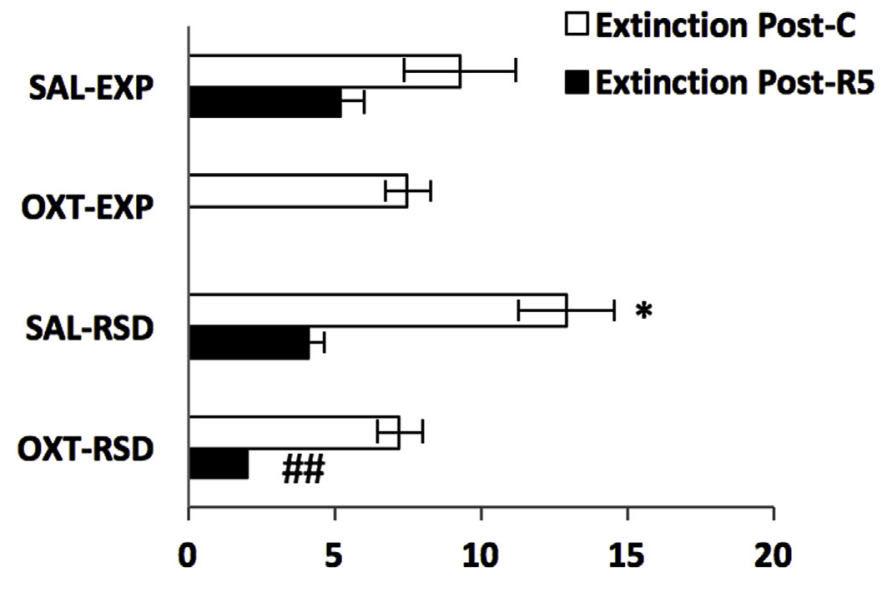

Number of extinction sessions

Fig. 4. Effect of oxytocin administration before each social defeat on the number of sessions needed to extinguish the preference induced by $10 \mathrm{mg} / \mathrm{kg}$ of cocaine. White bars represent the preference induced by $10 \mathrm{mg} /$ $\mathrm{kg}$ cocaine while grey bars represent the preference reinstated with a priming dose of $5 \mathrm{mg} / \mathrm{kg}$ cocaine. * $\mathrm{p}<0.05$ significant difference in the number of extinction sessions versus the oxytocin (OXT) groups. Bonferroni's test \#\#\#p $<0.001$ significant difference in the number of extinctions sessions versus saline (SAL) groups.

defeated animals pretreated with oxytocin OXT-RSD ( $p<0.001)$. No reinstatement was observed in non-stressed mice treated with oxytocin (SAL-EXP). Again, differences were observed in the time needed to extinguish this preference, since the OXT-RSD group required less extinction sessions ( 2 sessions) than the SAL-EXP $(\chi 2=10.193$; $\mathrm{p}=0.001)(8$ sessions $)$ and SAL-RSD $(\chi 2=10.111 ; \mathrm{p}=0.001)(6$ sessions) groups.

3.6. Oxytocin reduces the increased cocaine locomotor sensitization induced by social defeat stress

Fig. 5 displays the scores during the first 10 min of induced motor activity in animals after a motor sensitization protocol. The ANOVA revealed an effect of the variables Treatment $[F(3,50)=4.111$; $\mathrm{p}<0.01]$ and Induction-treatment $[\mathrm{F}(1,50)=38.854 ; \mathrm{p}<0.001]$. Post-hoc analyses showed that animals treated with cocaine during the induction phase (C-SAL-EXP, C-SAL-RSD, C-OXT-EXP, and C-OXT-RSD) were more reactive to a challenge dose of $5 \mathrm{mg} / \mathrm{kg}$ than those treated with saline (S-SAL-EXP, S-SAL-RSD, S-OXT-EXP, and S-OXT-RSD) ( $\mathrm{p}<0.001$ ). Additionally, RSD induced cross-sensitization to cocaine, since saline defeated animals (S-SAL-RSD) exhibited higher levels of motor activity than their non-stressed counterparts (S-SAL-EXP) $(\mathrm{p}<0.05)$, an effect that was not registered in defeated animals pretreated with oxytocin (see Fig. 5).

3.7. Repeated social defeat increases cocaine intake in the acquisition phase of cocaine self-administration

Following the criteria of acquisition, the percentage of mice that acquired cocaine self-administration behavior was $47.8 \%$ for EXP-SAL $(\mathrm{n}=23), 47.6 \%$ for RSD-SAL $(\mathrm{n}=21), 41.2 \%$ for EXP-OXT $(\mathrm{n}=17)$ and $45 \%$ for RSD-OXT $(n=20)$. Chi-squared analysis showed no significant differences between the groups $(\chi 2=0.217 ; \mathrm{p}>0.05)$. A two-way ANOVA of total cocaine intake (see Fig. 6A) showed a main effect of Stress $[F(1,33)=4.604 ; p<0.05]$, indicating that mice exposed to RSD consumed more cocaine than non-stressed mice. In relation to the day of acquisition (see Fig. 6B), the two-way ANOVA showed no significant differences between groups. The cocaine infusions received throughout the acquisition phase (Fig. 6C) were calculated by means of a four-way ANOVA (Treatment, Stress, Days and Holes as factors of variations), revealing a main effect of Days $[\mathrm{F}$ $(9,297)=3.538 ; \mathrm{p}<0.001]$, Hole $[\mathrm{F}(1,33)=32.630 ; \mathrm{p}<0.001]$, a tendency for Stress factor $[\mathrm{F}(1,33)=3.725 ; \mathrm{p}=0.062]$; interaction between Hole and Stress [F $(1,33)=5.428 ; \mathrm{p}<0.05]$ and Hole and Days $[\mathrm{F}(9,297)=4.941 ; \mathrm{p}<0.001]$; and a tendency between Days and Stress $[F(9,297)=1.893 ; p=0.053]$. Finally, we obtained an interaction between Days, Hole and Stress $[F(9,297)=2.263$, $\mathrm{p}<0.05]$. Bonferroni post-hoc analysis revealed that animals exposed to RSD engaged in a higher number of active infusions than nonstressed mice $(p<0.05)$. Bonferroni's post-hoc analysis of Hole and Days showed that RSD mice were capable of discriminating between the holes from the first day of acquisition until day 10, ( $<<0.05$, in all the cases), whereas non-stressed mice discriminated only on days $3,4,5,6$, 8 and 9 ( $\mathrm{p}<0.05$, in all the cases). Additionally, the results showed that mice exposed to RSD performed more active infusions than non-

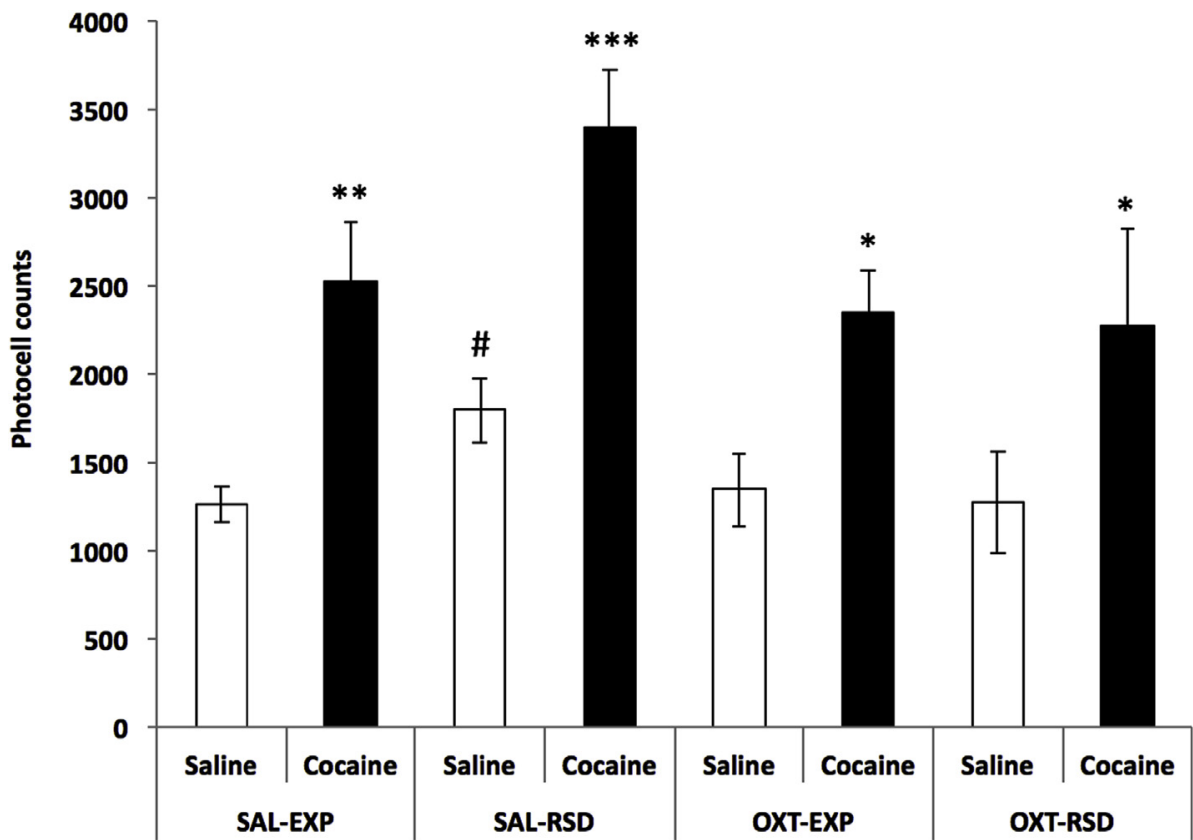

Fig. 5. Administration of $1 \mathrm{mg} / \mathrm{kg}$ of oxytocin before each social defeat blocks the increased locomotor sensitization to cocaine induced by social defeat stress. During the induction phase, half of the animals in each group received pretreatment with saline (S) (S-SAL-EXP $\mathrm{n}=8$; S-SAL-RSD $\mathrm{n}=8$; S-OXT-EXP $\mathrm{n}=6$; S-OXT-RSD $\mathrm{n}=6$ ) and the other half received $25 \mathrm{mg} / \mathrm{kg}$ cocaine per day (C) (CSAL-EXP $\mathrm{n}=9$; C-SAL-RSD $\mathrm{n}=8$; C-OXT-EXP $\mathrm{n}=7$; C-OXT-RSD $\mathrm{n}=6$ ) on three consecutive days. Data presented as mean values \pm S.E.M. during the first 10-min period of locomotor activity in photocell counts. Bonferroni's test * p $<0.05, * * p<0.01$, $* * * \mathrm{p}<0.001$ significant difference with the corresponding saline induction (S) group; $\# \mathrm{p}<0.001$ significant difference with respect to the corresponding Exploration (EXP) group. 
A

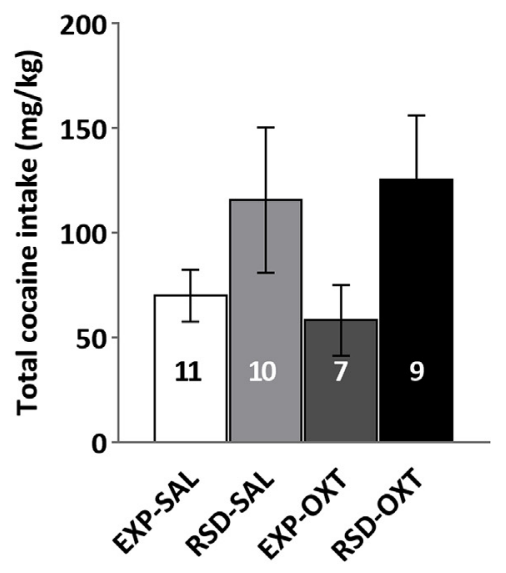

B

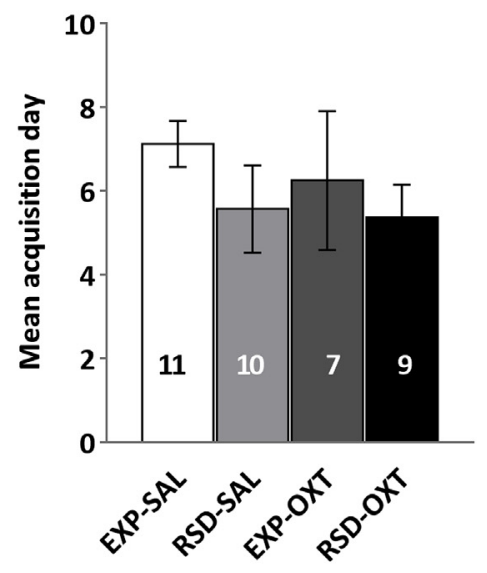

C

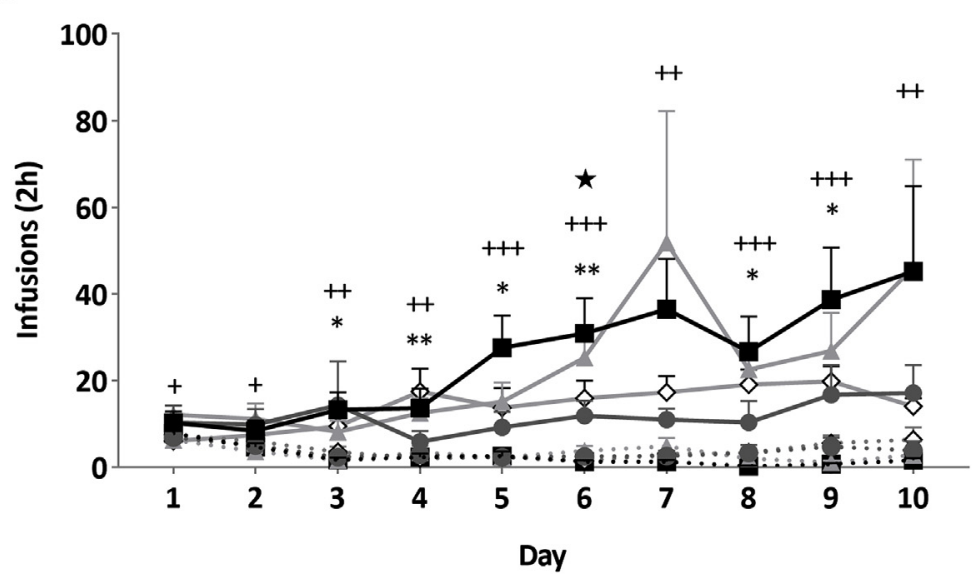

$\diamond \quad$ EXP-SAL Active Hole

$\diamond$. EXP-SAL Inactive Hole

- RSD-SAL Active Hole

-A. RSD-SAL Inactive Hole

- EXP-OXT Active Hole

- EXP-OXT Inactive Hole

RSD-OXT Active Hole

RSD-OXT Inactive Hole

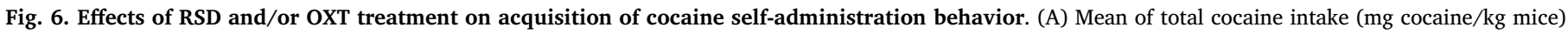

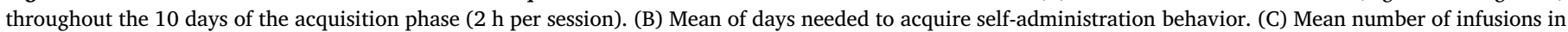

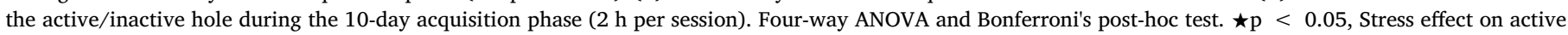

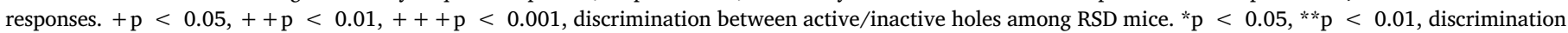
between active/inactive holes among EXP mice. Data are expressed as mean \pm S.EM. ( $n=7$ to 11 ).

stressed mice on day $6(\mathrm{p}<0.05)$. No effect of OXT treatment was observed.

\subsection{Oxytocin administration reduces the number of days needed to extinguish cocaine seeking-behavior and reverses the cocaine-seeking induced by repeated social defeat after a cocaine priming}

The percentage of mice in which self-administration behavior was extinguished did not differ between groups $(\chi 2=2.091 ; \mathrm{p}>0.05)$ : 72.7\% (EXP-SAL, $\mathrm{n}=11$ ), 70\% (RSD-SAL, $\mathrm{n}=10$ ), 57.1\% (EXP-OXT, $\mathrm{n}=7$ ) and $88.9 \%$ (RSD-OXT, $\mathrm{n}=9$ ). A two-way ANOVA of day of extinction (see Fig. 7A) demonstrated an effect of Treatment [F $(1,23)=15.468 ; p<0.01]$, a tendency for Stress $[F(1,23)=3.942$; $\mathrm{p}=0.059]$ and an interaction between Treatment and Stress [F $(1,23)=6.853 ; p<0.05]$. Bonferroni's post-hoc test revealed that mice in the EXP-OXT group needed fewer days for cocaine-seeking behavior to be extinguished than the EXP-SAL ( $<<0.001$ ) and RSDOXT groups $(\mathrm{p}<0.01)$. To compare behaviors during the First Extinction Day, the Last Extinction Day and the Reinstatement Day (see Fig. 7B), a four-way ANOVA was performed and showed an effect of Days $[F(2,46)=9.906, p<0.001]$ and Hole $[F(1,23)=27.139$; $\mathrm{p}<0.001]$, and interactions between Days and Stress [F $(2,46)=3.194 ; \mathrm{p}<0.05]$, Hole and Days $[\mathrm{F}(2,46)=10.938$; $\mathrm{p}<0.001]$, Days, Treatment and Stress $[\mathrm{F}(2,46)=4.541 ; \mathrm{p}<0.05]$, Hole, Treatment and Stress $[\mathrm{F}(1,23)=6.861 ; \mathrm{p}<0.05]$, Days, Hole and Stress $[\mathrm{F}(2,46)=3.565 ; \mathrm{p}<0.05]$ and between all the factors (Days, Hole, Treatment and Stress) $[\mathrm{F}(2,46)=3.390 ; \mathrm{p}<0.05]$. The Days effect revealed a lower number of responses during the Last Extinction Day in comparison with the First Extinction Day $(\mathrm{p}<0.001)$ and an increased number of responses on the Reinstatement Day in comparison with the Last Extinction Day $(\mathrm{p}<0.01$ ). The Hole effect showed active responses were stronger than inactive responses ( $p<0.001$ ). Bonferroni's post-hoc analysis of Stress and Days demonstrated that both groups exhibited more responses during the First Extinction Day than the Last Extinction Day ( $\mathrm{p}<0.01$ in both cases). The interaction Days and Hole showed that animals displayed more active responses during the First Extinction Day than on the Last Extinction Day $(p<0.01)$ and more active responses on the Reinstatement Day versus the Last Extinction Day $(\mathrm{p}<0.01)$. This interaction also highlighted a discrimination between holes on all the days evaluated (First Extinction Day p $<0.001$, Last Extinction Day p $<0.05$ and Reinstatement Day $\mathrm{p}<0.001$ ). Interaction of Treatment, Stress and Days revealed a higher response in the RSD-OXT group in comparison with the RSD-SAL group during the Last Extinction Day $(\mathrm{p}<0.05)$ and more responses in the RSD-SAL group than in the EXPSAL group during the Reinstatement Day $(\mathrm{p}<0.01)$. Moreover, EXP- 
A

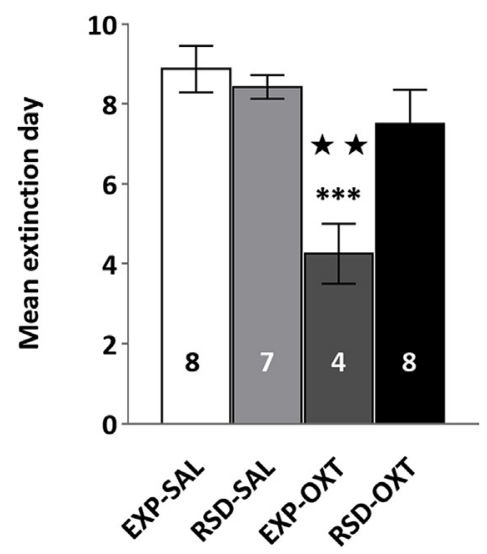

B

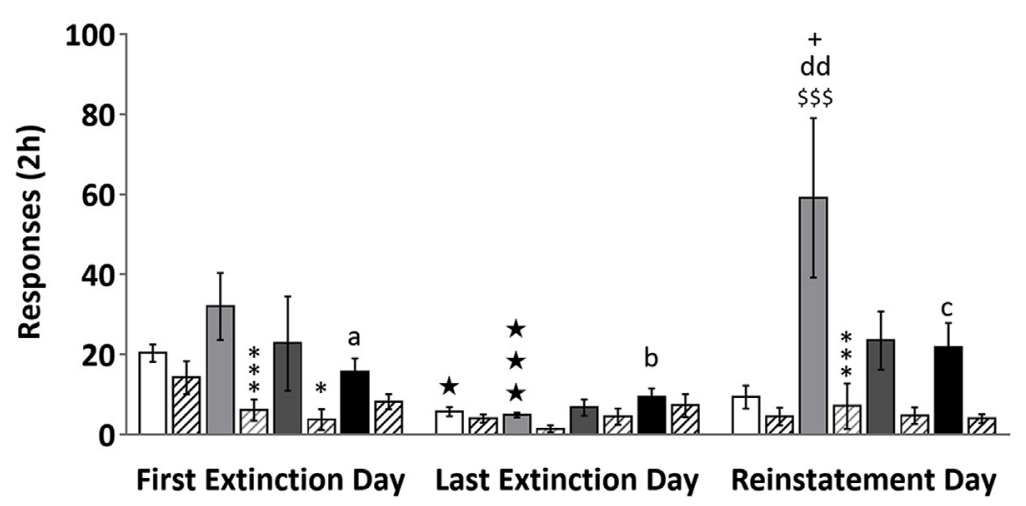

EXP-SAL Active Hole

$\square \quad$ EXP-SAL Inactive Hole

RSD-SAL Active Hole

曰 RSD-SAL Inactive Hole

$\square \quad$ EXP-OXT Active Hole

曰 EXP-OXT Inactive Hole

RSD-OXT Active Hole

■ RSD-OXT Inactive Hole

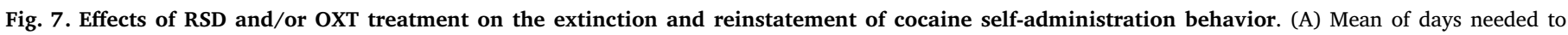

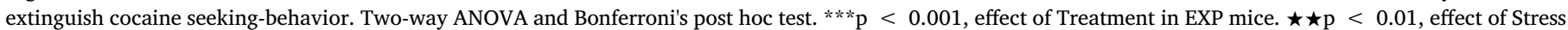

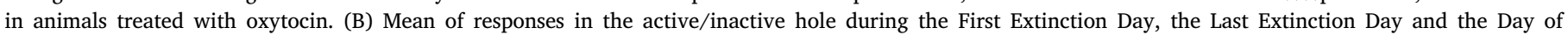

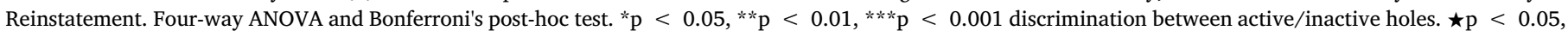

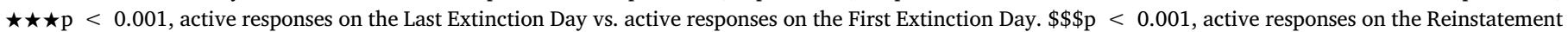

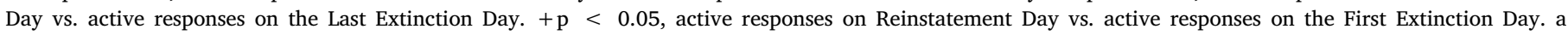

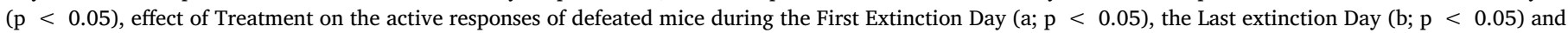

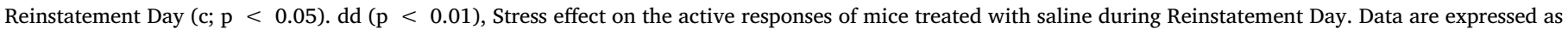
mean \pm S.E.M. ( $\mathrm{n}=4$ to 8 ).

SAL $(\mathrm{p}<0.01)$ and RSD-SAL $(\mathrm{p}<0.001)$ groups exhibited decreased responses on the Last Extinction Day compared with the first extinction day. However, only the RSD-SAL group displayed significantly increased responses on the Reinstatement Day compared with the Last Extinction Day $(\mathrm{p}<0.001)$. Interaction between Treatment, Stress and Hole was stronger in the RSD-SAL group compared with EXP-SAL $(p<0.01)$ and RSD-OXT $(p<0.05)$ groups. This interaction also highlighted discrimination between holes by the RSD-SAL $(\mathrm{p}<0.001)$ and EXP-OXT $(\mathrm{p}<0.05)$ groups. There was a decrease in the interaction between Stress, Days and Hole during the Last Extinction Day in comparison with the First Day of Extinction, independently of the Stress experience. This interaction also shows that RSD mice displayed a preference for the active hole during the First Extinction Day $(\mathrm{p}<0.01)$, Last Extinction Day $(\mathrm{p}<0.05)$ and Reinstatement Day ( $<<0.001$ ), while in the EXP groups, this preference was evident only on the First Day of Extinction ( $<<0.05$ ). Bonferroni's post-hoc test of all the factors revealed more active responses on Reinstatement Day among RSD-SAL mice than in the EXP-SAL group ( $\mathrm{p}<0.01$ ), demonstrating that RSD increased cocaine seeking-behavior during the reinstatement phase. We also observed a significant decrease of active responses in the EXP-SAL ( $\mathrm{p}<0.05$ ) and RSD-SAL groups ( $\mathrm{p}<0.001)$ on the Last Extinction Day in comparison with the First Extinction Day. In addition, the interaction between all factors on Reinstatement day was more pronounced in RSD-SAL mice than in the EXP-SAL group ( $\mathrm{p}<0.01$ ), suggesting that RSD increased vulnerability to the reinstatement of cocaine-seeking. Moreover, the RSD-SAL group was the only one capable of discriminating between holes during the day of reinstatement ( $\mathrm{p}<0.001$ ), and the only one in which the number of active responses was significantly higher on Reinstatement Day compared with the Last Extinction Day $(\mathrm{p}<0.05)$ and even with the First Extinction Day $(\mathrm{p}<0.05)$. This result means that the RSD-SAL group was the only one in which cocaine-seeking behavior was reinstated after an i.p cocaine priming. Ultimately, RSD-OXT mice performed stronger responses than the RSD-SAL group during the Last Day of Extinction $(\mathrm{p}<0.05)$. However, the RSD-OXT group showed weaker responses on the First Day of Extinction $(\mathrm{p}<0.05)$ and on Reinstatement Day ( $p<0.05$ ) than their RSD-SAL counterparts, suggesting that OXT treatment decreased the vulnerability to reinstate cocaine-seeking induced by RSD.

\section{Discussion}

Our results confirm that elevated levels of OXT when experiencing social defeat stress can block the long-lasting effects of this type of stress. OXT counteracts the anxiety induced by RSD and modifies BDNF levels in all the structures studied. RSD induced increases in the 
motivational effects of cocaine. Administration of OXT before each SD prevented RSD-induced increases in the conditioned rewarding effects of cocaine in the CPP, favored the extinction of cocaine-associated memories in both the CPP and SA paradigms, and decreased reinstatement of cocaine-seeking behavior in the SA.

Firstly, as the animals experienced the four SD episodes under the effect of OXT, it was necessary to confirm that the mice were actually socially defeated. The ethological analysis of the social encounter showed that resident mice threatened and attacked both OXT- and saline-treated mice to the same extent. Even more threats were observed during the last social encounter when the residents were confronted with mice treated with OXT. On the other hand, the intruder mice treated with OXT displayed less avoidance behavior during the last social defeat episode. In spite of these differences, we can conclude that OXT-treated mice experience similar SD to saline-treated counterparts, exhibiting similar behaviors to those observed in previous reports (Montagud-Romero et al., 2017).

It is well known that SD induces a clear anxiogenic effect (Albrechet-Souza et al., 2017; Macedo et al., 2018), which is completely blocked by OXT administration. Although data are controversial (for example, Grippo et al., 2012), many studies indicate that OXT exerts an anxiolytic effect in both sexes and even in aged rats (Balmus et al., 2018; Waldherr and Neumann, 2007). However, we did not observe any OXT effect on non-stressed mice. On the other hand, acute or chronic administration of OXT reduces anxiety-related behavior in stressed rodents (Ring et al., 2006; Slattery and Neumann, 2010; Windle et al., 1997). In agreement with our results, Lukas et al. (2011) showed that the loss of social preference and social avoidance in response to a single SD could be restored by intracerebroventricular infusion of OXT $20 \mathrm{~min}$ before the social preference test. In this sense, our results demonstrate that OXT administration before social stress can diminish the long-lasting increase in anxiety observed in defeated animals.

Numerous reports show that SD stress induces prolonged BDNF expression in the VTA and NAc, which have been associated with depressive-like symptoms (Berton et al., 2006; Fanous et al., 2010; Krishnan et al., 2007; Nikulina et al., 2012), although Miczek et al. (2011) observed an increase in tegmental BDNF in episodically defeated rats, whereas continuously subordinate rats showed suppressed BDNF levels. In the HIP, a reduction, an increase or a lack of changes after exposure to SD have been reported (Coppens et al., 2011; Duclot and Kabbaj., 2013; Lagace et al., 2010; Pizarro et al., 2004; Taylor et al., 2011; Tsankova et al., 2006). Previous studies in the PFC have described increases or decreases of BDNF immediately after social stress, without changes four weeks after stress (Fanous et al., 2010; Wang et al., 2018). In our study RSD did not affect BDNF in either of the structures evaluated. In previous work in our laboratory, we observed a down-regulation in proBDNF expression - a role in contrast to that of BDNF - in the NAc of defeated mice three weeks after the last social stress episode (Montagud-Romero et al., 2017). Interestingly, our results showed that RSD interacted with the OXT treatment, increasing the levels of BDNF in the STR and HIP, while paradoxically decreasing BDNF levels in the PFC.

Although there have been several reports of the positive effects of OXT in rats exposed to stress (Leuner et al., 2011; Cohen et al., 2010), few studies have focused on the relation between OXT, stress and BDNF. Dayi and coworkers (2015) described how OXT administration in rats exposed to restraint stress increased the expression of BDNF in the HIP, which correlated with an improvement of the cognitive deficit induced by stress. Therefore, in line with the present results, the amelioration of stress effects seems to be related to an increase of BDNF. Moreover, antidepressant administration also increased the expression of BDNF in the PFC, NAc and HIP after SD (Yang et al., 2016a,b). It is likely that synaptogenesis, including BDNF-TrkB signaling in the PFC and HIP, may underlie this sustained antidepressant effect. Indeed, current data suggest that BDNF plays a key role in the antidepressant response (Björkholm and Monteggia, 2016).

Although both are related to stress response, acute social stress has been shown to induce DNA methylation in OXTR but not in the BDNF gene (Unternaehrer et al., 2012). Emotional contagion-resistant mice characterized by reduced sociability - display elevated concentrations of OXT but a reduced density of TrkB receptors in brain areas relevant to behavior (Laviola et al., 2017). Havranek et al. (2015) demonstrated that administration of OXT to the lateral ventricle of rats induces a significant increase of mRNA and protein levels of BDNF in the HIP. Additionally, Dayi et al. (2015) reported that administration of OXT to stressed animals increased the expression of BDNF in the HIP. In this way, the amelioration of the effects of stress appears to be related to an increase of BDNF. All of this evidence suggests that OXT exerts anxiolytic and antidepressant effects and decreases the stress response by modulating the CRF-HPA axis (Baracz et al., 2018). Our results demonstrate that OXT treatment increases BDNF levels in the STR and HIP; however, this increase is higher in defeated animals, suggesting that OXT exerts an antidepressant-like effect by modulating the stress response. In contrast with previous reports, we did not observe an increase in BDNF levels in the PFC after OXT treatment; in fact, the opposite was observed, suggesting that alternative mechanisms are involved in such an interaction.

The CPP paradigm evaluates the conditioned motivational properties of drugs (Tzschentke, 2007), and is also used to test the reinstatement of drug-seeking after extinction (Aguilar et al., 2009). In accordance with previous reports, socially defeated mice underwent a long-lasting increase in the conditioned rewarding effects of cocaine, developing CPP with a non-effective dose of cocaine (Ferrer-Pérez et al., 2018). On the other hand, all groups conditioned with an effective $(10 \mathrm{mg} / \mathrm{kg})$ dose of cocaine in the CPP showed a preference that was reinstated with successive smaller doses of cocaine, as previously reported (Maldonado et al., 2006; Montagud-Romero et al., 2016b; Rodríguez-Arias et al., 2009). OXT administration before each SD blocked the increased preference observed in defeated mice conditioned with $1 \mathrm{mg} / \mathrm{kg}$ of cocaine and induced a faster extinction of the memories associated with $10 \mathrm{mg} / \mathrm{kg}$ of cocaine CPP in stressed animals. Although no differences in reinstatement were observed in defeated mice after OXT treatment, non-stressed animals pretreated with OXT did not present reinstatement with a priming dose of $5 \mathrm{mg} / \mathrm{kg}$, in contrast to controls, which did.

In agreement with previous reports, SD increased vulnerability to cocaine SA (e.g. Boyson et al., 2011; Burke and Miczek, 2015; Leonard et al., 2017; Yap et al., 2015). Socially defeated mice consumed more cocaine than non-stressed animals, with no OXT effect being detected. However, OXT administration reduced the number of days needed to extinguish cocaine-seeking behavior. The number of active responses fell between the first and last extinction day in all the groups, except for the OXT-treated defeated group, which showed a reduced number of responses from the first day of extinction. In response to a cocainepriming dose, only defeated saline-treated animals showed an increased number of active responses, while OXT treatment reverted this effect. Several reports have pointed out that acute OXT administration reduces cocaine intake and reinstatement of cocaine SA (Leong et al., 2016, 2017; Sarnyai and Kovács, 1994; Zhou et al., 2014), but given that in our experiments OXT was administered weeks before initiating the procedure, we believe that OXT does not affect cocaine SA, but rather only the changes induced by RSD.

OXT prevented the increase in the conditioned rewarding effects of cocaine when a non-effective dose was administered in the CPP, but it did not modify the enhanced cocaine SA induced by RSD. It also decreased cocaine-priming-induced reinstatement of SA, but it did not affect reinstatement of the preference in the CPP. Both paradigms are used to evaluate the motivational value of a drug, but each assesses different aspects of drug-induced reward and, thus, different characteristics of relapse and addictive behavior. SA evaluates the primary rewarding properties of drugs using operant conditioning, where a 
reinstatement after extinction implies the restoration of a concrete operant response. On the other hand, CPP is based on Pavlovian conditioning and it evaluates cue-elicited drug-taking behavior by assessing the incentive value of drug-associated cues and the reinstatement of CPP (consisting of the reappearance of approach behavior towards a drug-associated context) (Aguilar et al., 2009). Interestingly, in both paradigms, OXT accelerates the time needed to extinguish operant behavior or conditioned preference. Therefore, we can affirm that OXT diminishes the potency of the memories associated with drug use. Numerous reports have shown that OXT modifies learning and memory processes, mostly through hippocampal and related limbic mechanisms (Gaffori and De Wied, 1988; Gard et al., 2012; Kovács et al., 1979). However, OXT has a long-term inhibitory effect during acquisition, retention, consolidation and retrieval (Kovács and de Wied, 1994 for review; Boccia et al., 1998; Boccia and Baratti, 2000). More importantly, OXT seems to play a role in behavioral flexibility and adaptive responses (Chini et al., 2014), and may increase the cognitive flexibility necessary to acquire new learning during the extinction process.

Increased motor response after intermittent drug administration is defined as behavioral sensitization (Kalivas and Stewart, 1991; Steketee and Kalivas, 2011). As expected, all the groups that received cocaine pretreatment in our experimental protocol developed cocaine motor sensitization. In addition, SD induced cross-sensitization with cocaine. Socially defeated mice pretreated with saline showed comparable enhancement of motor activity to that observed in those pretreated with cocaine (Ferrer-Pérez et al., 2018; Kalivas et al., 1998; Lu et al., 2001). As with the effect observed in our CPP and SA experiments, OXT administration prior to each social defeat completely abolished crosssensitization, without affecting cocaine-induced sensitization.

Our results demonstrate that OXT is capable of reverting the longlasting increase in anxiety, in sensitivity to the motivational value of cocaine, in cross-sensitization, and in BDNF changes induced by social stress. In line with our results, several reports have indicated that OXT represents a potential new therapeutic approach for stress-induced psychiatric disorders (Ebner et al., 2000; Engelmann et al., 1999; Litvin et al., 2011; Wang et al., 2018). Also, in agreement with our results, a recent report showed that a single dose of OXT, systemically or within the bed nucleus of the stria terminalis, reverses stress-induced social avoidance in female mice (Duque-Wilckens et al., 2018). Based on previous reports (see review Sarnyai and Kovács, 2014), we propose that OXT exerts this effect independently of other mechanisms affecting the stress response, exerting an action on learning and memory processes associated with cocaine. Cocaine induces synaptic plasticity in neural systems that are vital for the development of addiction (reviewed by Hyman et al., 2006; Malenka and Bear, 2004), modifying a number of signaling cascades, including BDNF, whose elevated expression has been associated with susceptibility to drugs of abuse (Berhow et al., 1995; Flanagin et al., 2006; Guillin et al., 2001; Hall et al., 2003; Thomas et al., 2008; Tsai, 2007).

\section{Conclusions}

In conclusion, our results show that the long-lasting effects of RSD on anxiety and the motivational effects of cocaine are counteracted if OXT is administered before this type of stress is experienced. We hypothesize that, among other mechanisms, alterations in BDNF expression are involved in these protective effects. In this way, our results confirm the potential protective effects of OXT against the pathogenic effects of social stress.

\section{Conflicts of interest}

This work has not been published previously and is not under consideration for publication elsewhere. The authors have no possible conflict of interest in the carrying out and reporting of this research.

\section{Funding sources}

This work was supported by the Ministerio de Economía y Competitividad, Dirección General de Investigación, [grant numbers PSI2014-51847-R and PSI 2017-83023-R]; Spanish Ministry of Economy, Innovation and Competiveness (SAF2016-75347-R). Instituto de Salud Carlos III, Red de Trastornos Adictivos (RTA) [grant numbers RETICS RD06/0001/1006; RD12/0028/0005; and RD/16/0017/0010] and Unión Europea, Fondos FEDER "A way to build Europe". The Department of Experimental and Health Sciences (UPF) is an "Unidad de Excelencia María de Maeztu" funded by the MINECO (Ref. MDM2014-0370). A.C-Z received CONACYT grant from the Government of Mexico. M.A.L. and C.F.P received FPU grant from the Spanish Ministry of Economy, Innovation and Competiveness (15/02492 and 14/02279). The authors declare no conflicts of interest.

\section{Acknowledgements}

We wish to thank Brian Normanly for his English language editing.

\section{References}

Aguilar, M.A., Rodríguez-Arias, M., Miñarro, J., 2009. Neurobiological mechanisms of the reinstatement of drug-conditioned place preference. Brain Res. Rev. 59, 253-277. https://doi.org/10.1016/j. brainresrev.2008.08.002.

Albrechet-Souza, L., Viola, T.W., Grassi-Oliveira, R., Miczek, K.A., de Almeida, R.M.M., 2017. Corticotropin releasing factor in the bed nucleus of the stria terminalis in socially defeated and non-stressed mice with a history of chronic alcohol intake. Front. Pharmacol. 8, 762. https://doi.org/10.3389/fphar.2017.00762.

Arenas, M.C., Daza-Losada, M., Vidal-Infer, A., Aguilar, M.A., Miñarro, J., RodríguezArias, M., 2014. Capacity of novelty-induced locomotor activity and the hole-board test to predict sensitivity to the conditioned rewarding effects of cocaine. Physiol. Behav. 133, 152-160. https://doi.org/10.1016/j.physbeh.2014.05.028.

Balmus, I.M., Lefter, R., Ciobica, A., Antioch, I., Ababei, D., Dobrin, R., 2018. Preliminary data on some behavioral changes induced by short-term intraperitoneal oxytocin administration in aged rats. Psychiatr. Danub. 30, 91-98. https://doi.org/10.24869/ psyd.2018.91.

Baracz, S.J., Cornish, J.L., 2016. The neurocircuitry involved in oxytocin modulation of methamphetamine addiction. Front. Neuroendocrinol. 43, 1-18. https://doi.org/10. 1016/j.yfrne.2016.08.001.

Baracz, S.J., Everett, N.A., Cornish, J.L., 2018. The impact of early life stress on the central oxytocin system and susceptibility for drug addiction: applicability of oxytocin as a pharmacotherapy. Neurosci. Biobehav. Rev. https://doi.org/10.1016/j. neubiorev.2018.08.014.

Berhow, M.T., Russell, D.S., Terwilliger, R.Z., Beitner-Johnson, D., Self, D.W., Lindsay, R.M., Nestler, E.J., 1995. Influence of neurotrophic factors on morphine- and cocaineinduced biochemical changes in the mesolimbic dopamine system. Neuroscience 68, 969-979. https://doi.org/10.1016/0306-4522(95)00207-Y.

Berton, O., McClung, C.A., DiLeone, R.J., Krishnan, V., Renthal, W., Russo, S.J., Graham, D., Tsankova, N.M., Bolanos, C.A., Rios, M., Monteggia, L.M., Self, D.W., Nestler, E.J., 2006. Essential role of BDNF in the mesolimbic dopamine pathway in social defeat stress. Science 311, 864-868. https://doi.org/10.1126/science.1120972.

Björkholm, C., Monteggia, L.M., 2016. BDNF - a key transducer of antidepressant effects. Neuropharmacology 102, 72-79. https://doi.org/10.1016/j.neuropharm.2015.10. 034.

Boccia, M.M., Baratti, C.M., 2000. Involvement of central cholinergic mechanisms in the effects of oxytocin and an oxytocin receptor antagonist on retention performance in mice. Neurobiol. Learn. Mem. 74, 217-228. https://doi.org/10.1006/nlme.1999. 3954.

Boccia, M.M., Kopf, S.R., Baratti, C.M., 1998. Effects of a single administration of oxytocin or vasopressin and their interactions with two selective receptor antagonists on memory storage in mice. Neurobiol. Learn. Mem. 69, 136-146. https://doi.org/10. 1006/nlme.1997.3817.

Boyson, C.O., Holly, E.N., Shimamoto, A., Albrechet-Souza, L., Weiner, L.A., DeBold, J.F., Miczek, K.A., 2014. Social stress and CRF-dopamine interactions in the VTA: role in long-term escalation of cocaine self-administration. J. Neurosci. 34, 6659-6667. https://doi.org/10.1523/JNEUROSCI.3942-13.2014.

Boyson, C.O., Miguel, T.T., Quadros, I.M., DeBold, J.F., Miczek, K.A., 2011. Prevention of social stress-escalated cocaine self-administration by CRF-R1 antagonist in the rat VTA. Psychopharmacology 218, 257-269. https://doi.org/10.1007/s00213-0112266-8.

Burke, A.R., Miczek, K.A., 2015. Escalation of cocaine self-administration in adulthood after social defeat of adolescent rats: role of social experience and adaptive coping behavior. Psychopharmacology 232, 3067-3079. https://doi.org/10.1007/s00213-.

Carson, D.S., Cornish, J.L., Guastella, A.J., Hunt, G.E., McGregor, I.S., 2010. Oxytocin decreases methamphetamine self-administration, methamphetamine hyperactivity, and relapse to methamphetamine-seeking behaviour in rats. Neuropharmacology 58 , 38-43. https://doi.org/10.1016/j.neuropharm.2009.06.018.

Chini, B., Leonzino, M., Braida, D., Sala, M., 2014. Learning about oxytocin: 
pharmacologic and behavioral issues. Biol. Psychiatry 76, 360-366. https://doi.org/ 10.1016/j.biopsych.2013.08.029.

Cohen, H., Kaplan, Z., Kozlovsky, N., Gidron, Y., Matar, M.A., Zohar, J., 2010. Hippocampal microinfusion of oxytocin attenuates the behavioural response to stress by means of dynamic interplay with the glucocorticoid-catecholamine responses. J. Neuroendocrinol. 22, 889-904. https://doi.org/10.1111/j.1365-2826.2010.02003.x.

Coppens, C.M., Siripornmongcolchai, T., Wibrand, K., Alme, M.N., Buwalda, B., de Boer, S.F., Koolhaas, J.M., Bramham, C.R., 2011. Social defeat during adolescence and adulthood differentially induce BDNF-regulated immediate early genes. Front. Behav. Neurosci. 5, 72. https://doi.org/10.3389/fnbeh.2011.00072.

Covington, H.E., Kikusui, T., Goodhue, J., Nikulina, E.M., Hammer, R.P., Miczek, K.A., 2005. Brief social defeat stress: long lasting effects on cocaine taking during a binge and zif268 mRNA expression in the amygdala and prefrontal cortex. Neuropsychopharmacology 30, 310-321. https://doi.org/10.1038/sj.npp.1300587.

Covington, H.E., Miczek, K.A., 2001. Repeated social-defeat stress, cocaine or morphine: effects on behavioral sensitization and intravenous cocaine self-administration "binges. Psychopharmacology 158, 388-398. https://doi.org/10.1007/ s002130100858.

Cox, B.M., Young, A.B., See, R.E., Reichel, C.M., 2013. Sex differences in methamphetamine seeking in rats: impact of oxytocin. Psychoneuroendocrinology 38 2343-2353. https://doi.org/10.1016/j.psyneuen.2013.05.005.

Dayi, A., Cetin, F., Sisman, A.R., Aksu, I., Tas, A., Gönenc, S., Uysal, N., 2015. The effects of oxytocin on cognitive defect caused by chronic restraint stress applied to adolescent rats and on hippocampal VEGF and BDNF levels. Med. Sci. Mon. Int. Med. J. Exp. Clin. Res. 21, 69-75. https://doi.org/10.12659/MSM.893159.

Daza-Losada, M., Rodríguez-Arias, M., Maldonado, C., Aguilar, M.A., Guerri, C., Miñarro, J., 2009. Acute behavioural and neurotoxic effects of MDMA plus cocaine in adolescent mice. Neurotoxicol. Teratol. 31, 49-59. https://doi.org/10.1016/j.ntt.2008. 07.005 .

Duclot, F., Kabbaj, M., 2013. Individual differences in novelty seeking predict subsequent vulnerability to social defeat through a differential epigenetic regulation of brainderived neurotrophic factor expression. J. Neurosci. 33, 11048-11060. https://doi. org/10.1523/JNEUROSCI.0199-13.2013.

Duque-Wilckens, N., Steinman, M.Q., Busnelli, M., Chini, B., Yokoyama, S., Pham, M., Laredo, S.A., Hao, R., Perkeybile, A.M., Minie, V.A., Tan, P.B., Bales, K.L., Trainor, B.C., 2018. Oxytocin receptors in the anteromedial bed nucleus of the stria terminalis promote stress-induced social avoidance in female California mice. Biol. Psychiatry 83, 203-213. https://doi.org/10.1016/j.biopsych.2017.08.024.

Ebner, K., Wotjak, C.T., Landgraf, R., Engelmann, M., 2000. A single social defeat experience selectively stimulates the release of oxytocin, but not vasopressin, within the septal brain area of male rats. Brain Res. 872, 87-92. https://doi.org/10.1016/ S0006-8993(00)02464-1.

Eckstein, M., Scheele, D., Weber, K., Stoffel-Wagner, B., Maier, W., Hurlemann, R., 2014. Oxytocin facilitates the sensation of social stress. Hum. Brain Mapp. 35, 4741-4750. https://doi.org/10.1002/hbm.22508.

Engelmann, M., Ebner, K., Landgraf, R., Holsboer, F., Wotjak, C.T., 1999. Emotional stress triggers intrahypothalamic but not peripheral release of oxytocin in male rats. J. Neuroendocrinol. 11, 867-872. https://doi.org/10.1046/j.1365-2826.1999.00403.x.

Fanous, S., Hammer, R.P., Nikulina, E.M., 2010. Short- and long-term effects of intermittent social defeat stress on brain-derived neurotrophic factor expression in mesocorticolimbic brain regions. Neuroscience 167, 598-607. https://doi.org/10.1016/ j.neuroscience.2010.02.064.

Ferrer-Pérez, C., Reguilón, M.D., Manzanedo, C., Aguilar, M.A., Miñarro, J., Rodríguez Arias, M., 2018. Antagonism of corticotropin-releasing factor CRF1receptors blocks the enhanced response to cocaine after social stress. Eur. J. Pharmacol. 823, 87-95. https://doi.org/10.1016/j.ejphar.2018.01.052.

Flanagin, B.A., Cook, E.H., De Wit, H., 2006. An association study of the brain-derived neurotrophic factor Val66Met polymorphism and amphetamine response. Am. J. Med. Genet. Part B Neuropsychiatr. Genet. 141, 576-583. https://doi.org/10.1002/ ajmg.b.30327.

Fumagalli, F., Di Pasquale, L., Caffino, L., Racagni, G., Riva, M.A., 2007. Repeated exposure to cocaine differently modulates BDNF mRNA and protein levels in rat striatum and prefrontal cortex. Eur. J. Neurosci. 26, 2756-2763. https://doi.org/10 1111/j.1460-9568.2007.05918.x.

Gaffori, O.J.W., De Wied, D., 1988. Bimodal effect of oxytocin on avoidance behavior may be caused by the presence of two peptide sequences with opposite action in the same molecule. Eur. J. Pharmacol. 147, 157-162. https://doi.org/10.1016/0014-2999(88) 90774-1.

Gard, P.R., Naylor, C., Ali, S., Partington, C., 2012. Blockade of pro-cognitive effects of angiotensin IV and physostigmine in mice by oxytocin antagonism. Eur. J. Pharmacol. 683, 155-160. https://doi.org/10.1016/j.ejphar.2012.02.048.

Gimpl, G., Fahrenholz, F., 2001. The oxytocin receptor system: structure, function, and regulation. Physiol. 81, 629-683. https://doi.org/10.1152/physrev.2001.81.2.629.

Grillon, C., Krimsky, M., Charney, D.R., Vytal, K., Ernst, M., Cornwell, B., 2013. Oxytocin increases anxiety to unpredictable threat. Mol. Psychiatr. 18, 958-960. https://doi. org $/ 10.1038 / \mathrm{mp} .2012 .156$.

Georgiou, P., Zanos, P., Hourani, S., Kitchen, I., Bailey, A., 2016. Cocaine abstinence induces emotional impairment and brain region-specific upregulation of the oxytocin receptor binding. Eur. J. Neurosci. 44, 2446-2454. https://doi.org/10.1111/ejn. 13348.

Grippo, A.J., Pournajafi-Nazarloo, H., Sanzenbacher, L., Trahanas, D.M., McNeal, N., Clarke, D.A., Porges, S.W., Sue Carter, C., 2012. Peripheral oxytocin administration buffers autonomic but not behavioral responses to environmental stressors in isolated prairie voles. Stress 15, 149-161. https://doi.org/10.3109/10253890.2011.605486. Guillin, O., Diaz, J., Carroll, P., Griffon, N., Schwartz, J.C., Sokoloff, P., 2001. BDNF controls dopamine D3receptor expression and triggers behavioural sensitization.
Nature 411, 86-89. https://doi.org/10.1038/35075076.

Hall, F.S., Drgonova, J., Goeb, M., Uhl, G.R., 2003. Reduced behavioral effects of cocaine in heterozygous brain-derived neurotrophic factor (BDNF) knockout mice. Neuropsychopharmacology 28, 1485-1490. https://doi.org/10.1038/sj.npp. 1300192.

Hammels, C., Pishva, E., De Vry, J., van den Hove, D.L.A., Prickaerts, J., van Winkel, R., Selten, J.P., Lesch, K.P., Daskalakis, N.P., Steinbusch, H.W.M., van Os, J., Kenis, G., Rutten, B.P.F., 2015. Defeat stress in rodents: from behavior to molecules. Neurosci. Biobehav. Rev. 59, 111-140. https://doi.org/10.1016/j.neubiorev.2015.10.006.

Han, X., DeBold, J.F., Miczek, K.A., 2017. Prevention and reversal of social stress-escalated cocaine self-administration in mice by intra-VTA CRFR1 antagonism. Psychopharmacology 234, 2813-2821. https://doi.org/10.1007/s00213-0174676-8.

Havranek, T., Zatkova, M., Lestanova, Z., Bacova, Z., Mravec, B., Hodosy, J., Strbak, V., Bakos, J., 2015. Intracerebroventricular oxytocin administration in rats enhances object recognition and increases expression of neurotrophins, microtubule-associated protein 2, and synapsin I. J. Neurosci. Res. 93, 893-901. https://doi.org/10.1002/ jnr.23559.

Heinrichs, M., Domes, G., 2008. Neuropeptides and social behaviour: effects of oxytocin and vasopressin in humans. Prog. Brain Res. 170, 337-350. https://doi.org/10.1016/ S0079-6123(08)00428-7.

Holly, E.N., Boyson, C.O., Montagud-Romero, S., Stein, D.J., Gobrogge, K.L., DeBold, J.F., Miczek, K.A., 2016. Episodic social stress-escalated cocaine self-administration: role of phasic and tonic corticotropin releasing factor in the anterior and posterior ventral tegmental area. J. Neurosci. 36, 4093-4105. https://doi.org/10.1523/JNEUROSCI. 2232-15.2016.

Hyman, S.E., Malenka, R.C., Nestler, E.J., 2006. NEURAL MECHANISMS OF ADDICTION: the role of reward-related learning and memory. Annu. Rev. Neurosci. 29, 565-598. https://doi.org/10.1146/annurev.neuro.29.051605.113009.

Hymel, K.A., Eans, S.O., Sitchenko, K.L., Gomes, S.M., Lukowsky, A.L., Medina, J.M., Sypek, E.I., Carey, A.N., McLaughlin, J.P., 2014. Stress-induced increases in depression-like and cocaine place-conditioned behaviors are reversed by disruption of memories during reconsolidation. Behav. Pharmacol. 25, 599-608. https://doi.org/ 10.1097/FBP.0000000000000074.

Johnson, Z.V., Young, L.J., 2017. Oxytocin and vasopressin neural networks: implications for social behavioral diversity and translational neuroscience. Neurosci. Biobehav. Rev. 76, 87-98. https://doi.org/10.1016/j.neubiorev.2017.01.034.

Kalivas, P.W., Pierce, R.C., Cornish, J., Sorg, B.A., 1998. A role for sensitization in craving and relapse in cocaine addiction. J. Psychopharmacol. 12, 49-53. https://doi.org/10. $1177 / 026988119801200107$.

Kalivas, P.W., Stewart, J., 1991. Dopamine transmission in the initiation and expression of drug- and stress-induced sensitization of motor activity. Brain Res. Rev. 16, 223-244. https://doi.org/10.1016/0165-0173(91)90007-U.

King, C.E., Griffin, W.C., Luderman, L.N., Kates, M.M., McGinty, J.F., Becker, H.C., 2017 Oxytocin reduces ethanol self-administration in mice. Alcohol Clin. Exp. Res. 41, 955-964. https://doi.org/10.1111/acer.13359.

Kirsch, P., 2005. Oxytocin modulates neural circuitry for social cognition and fear in humans. J. Neurosci. 25, 11489-11493. https://doi.org/10.1523/JNEUROSCI.398405.2005.

Kovács, G.L., Bohus, B., Versteeg, D.H.G., Ronald De Kloet, E., De Wied, D., 1979. Effect of oxytocin and vasopressin on memory consolidation: sites of action and catecholaminergic correlates after local microinjection into limbic-midbrain structures. Brain Res. 175, 303-314. https://doi.org/10.1016/0006-8993(79)91009-6.

Kovács, G.L., De Wied, D., 1994. Peptidergic modulation of learning and memory processes. Pharmacol. Rev. 46, 269-291.

Kovàcs, G.L., Faludi, M., Falkay, G., Telegdy, G., 1986. Peripheral oxytocin treatment modulates central dopamine transmission in the mouse limbic structures. Neurochem. Int. 9, 481-485. https://doi.org/10.1016/0197-0186(86)90138-5.

Kovàcs, G.L., Sarnyai, Z., Babarczi, E., Szabó, G., Telegdy, G., 1990. The role of oxytocindopamine interactions in cocaine-induced locomotor hyperactivity. Neuropharmacology 29, 365-368. https://doi.org/10.1016/0028-3908(90)90095-9.

Krishnan, V., Han, M.H., Graham, D.L., Berton, O., Renthal, W., Russo, S.J., LaPlant, Q., Graham, A., Lutter, M., Lagace, D.C., Ghose, S., Reister, R., Tannous, P., Green, T.A., Neve, R.L., Chakravarty, S., Kumar, A., Eisch, A.J., Self, D.W., Lee, F.S., Tamminga, C.A., Cooper, D.C., Gershenfeld, H.K., Nestler, E.J., 2007. Molecular adaptations underlying susceptibility and resistance to social defeat in brain reward regions. Cell 131, 391-404. https://doi.org/10.1016/j.cell.2007.09.018.

Lagace, D.C., Donovan, M.H., DeCarolis, N.A., Farnbauch, L.A., Malhotra, S., Berton, O. Nestler, E.J., Krishnan, V., Eisch, A.J., 2010. Adult hippocampal neurogenesis is functionally important for stress-induced social avoidance. Proc. Natl. Acad. Sci. Unit. States Am. 107, 4436-4441. https://doi.org/10.1073/pnas.0910072107.

Land, B.B., Bruchas, M.R., Schattauer, S., Giardino, W.J., Aita, M., Messinger, D., Hnasko, T.S., Palmiter, R.D., Chavkin, C., 2009. Activation of the kappa opioid receptor in the dorsal raphe nucleus mediates the aversive effects of stress and reinstates drug seeking. Proc. Natl. Acad. Sci. Unit. States Am. 106, 19168-19173. https://doi.org/ 10.1073/pnas.0910705106.

Laviola, G., Zoratto, F., Ingiosi, D., Carito, V., Huzard, D., Fiore, M., Macrì, S., 2017. Low empathy-like behaviour in male mice associates with impaired sociability, emotional memory, physiological stress reactivity and variations in neurobiological regulations. PLoS One 12. https://doi.org/10.1371/journal.pone.0188907.

Le Foll, B., Diaz, J., Sokoloff, P., 2005. A single cocaine exposure increases BDNF and D3receptor expression: implications for drug-conditioning. Neuroreport 16, 175-178. https://doi.org/10.1097/00001756-200502080-00022.

Leonard, M.Z., DeBold, J.F., Miczek, K.A., 2017. Escalated cocaine "binges" in rats: enduring effects of social defeat stress or intra-VTA CRF. Psychopharmacology 234, 2823-2836. https://doi.org/10.1007/s00213-017-4677-7. 
Leong, K.C., Freeman, L.R., Berini, C.R., Ghee, S.M., See, R.E., Reichel, C.M., 2017 Oxytocin reduces cocaine cued fos activation in a regionally specific manner. Int. J. Neuropsychopharmacol. 20, 844-854. https://doi.org/10.1093/ijnp/pyx058.

Leong, K.C., Zhou, L., Ghee, S.M., See, R.E., Reichel, C.M., 2016. Oxytocin decreases cocaine taking, cocaine seeking, and locomotor activity in female rats. Exp. Clin. Psychopharmacol 24, 55-64. https://doi.org/10.1037/pha0000058.

Leuner, B., Caponiti, J.M., Gould, E., 2011. Oxytocin stimulates adult neurogenesis even under conditions of stress and elevated glucocorticoids. Hippocampus 22, 861-868. https://doi.org/10.1002/hipo.20947.

Light, K.C., Grewen, K.M., Amico, J.A., Boccia, M., Brownley, K.A., Johns, J.M., 2004. Deficits in plasma oxytocin responses and increased negative affect, stress, and blood pressure in mothers with cocaine exposure during pregnancy. Addict. Behav. 29, 1541-1564. https://doi.org/10.1016/j.addbeh.2004.02.062.

Litvin, Y., Murakami, G., Pfaff, D.W., 2011. Effects of chronic social defeat on behavioral and neural correlates of sociality: vasopressin, oxytocin and the vasopressinergic V1b receptor. Physiol. Behav. 103, 393-403. https://doi.org/10.1016/j.physbeh.2011.03. 007.

Logrip, M.L., Zorrilla, E.P., Koob, G.F., 2012. Stress modulation of drug self-administration: implications for addiction comorbidity with post-traumatic stress disorder. Neuropharmacology 62, 552-564. https://doi.org/10.1016/j.neuropharm.2011.07. 007.

López-Arnau, R., Luján, M.A., Duart-Castells, L., Pubill, D., Camarasa, J., Valverde, O., Escubedo, E., 2017. Exposure of adolescent mice to 3,4-methylenedioxypyrovalerone increases the psychostimulant, rewarding and reinforcing effects of cocaine in adulthood. Br. J. Pharmacol. 174, 1161-1173. https://doi.org/10.1111/bph.13771.

Lu, L., Liu, D., Ceng, X., 2001. Corticotropin-releasing factor receptor type 1 mediates stress-induced relapse to cocaine-conditioned place preference in rats. Eur. J. Pharmacol. 415, 203-208. https://doi.org/10.1016/S0014-2999(01)00840-8.

Lukas, M., Neumann, I.D., 2014. Social preference and maternal defeat-induced social avoidance in virgin female rats: sex differences in involvement of brain oxytocin and vasopressin. J. Neurosci. Methods 234, 101-107. https://doi.org/10.1016/j jneumeth.2014.03.013.

Lukas, M., Toth, I., Reber, S.O., Slattery, D.A., Veenema, A.H., Neumann, I.D., 2011. The neuropeptide oxytocin facilitates pro-social behavior and prevents social avoidance in rats and mice. Neuropsychopharmacology 36, 2159-2168. https://doi.org/10. 1038/npp.2011.95.

Lumley, L.A., Charles, R.F., Charles, R.C., Hebert, M.A., Morton, D.M., Meyerhoff, J.L., 2000. Effects of social defeat and of diazepam on behavior in a resident-intruder test in male DBA/2 mice. Pharmacol. Biochem. Behav. 67, 433-447. https://doi.org/10. 1016/S0091-3057(00)00382-8.

Macedo, G.C., Morita, G.M., Domingues, L.P., Favoretto, C.A., Suchecki, D., Quadros, I.M.H., 2018. Consequences of continuous social defeat stress on anxiety- and depressive-like behaviors and ethanol reward in mice. Horm. Behav. 97, 154-161. https://doi.org/10.1016/j.yhbeh.2017.10.007.

MacFadyen, K., Loveless, R., Delucca, B., Wardley, K., Deogan, S., Thomas, C., Peris, J. 2016. Peripheral oxytocin administration reduces ethanol consumption in rats. Pharmacol. Biochem. Behav. 140, 27-32. https://doi.org/10.1016/j.pbb.2015.10. 014.

Maldonado, C., Rodríguez-Arias, M., Castillo, A., Aguilar, M.A., Miñarro, J., 2006. Gamma-hydroxybutyric acid affects the acquisition and reinstatement of cocaineinduced conditioned place preference in mice. Behav. Pharmacol. 17, 119-131. https://doi.org/10.1097/01.fbp.0000190685.84984.ec.

Malenka, R.C., Bear, M.F., 2004. LTP and LTD: an embarrassment of riches. Neuron 44 5-21. https://doi.org/10.1016/j.neuron.2004.09.012.

McGough, N.N.H., 2004. RACK1 and brain-derived neurotrophic factor: a homeostatic pathway that regulates alcohol addiction. J. Neurosci. 24, 10542-10552. https://doi org/10.1523/JNEUROSCI.3714-04.2004.

McLaughlin, J.P., Li, S., Valdez, J., Chavkin, T.A., Chavkin, C., 2006. Social defeat stressinduced behavioral responses are mediated by the endogenous kappa opioid system. Neuropsychopharmacology 31, 1241-1248. https://doi.org/10.1038/sj.npp 1300872.

McRae-Clark, A.L., Baker, N.L., Maria, M.M.S., Brady, K.T., 2013. Effect of oxytocin on craving and stress response in marijuana-dependent individuals: a pilot study. Psychopharmacology 228, 623-631. https://doi.org/10.1007/s00213-013-3062-4.

Meerlo, P., Koehl, M., Van Der Borght, K., Turek, F.W., 2002. Sleep restriction alters the hypothalamic-pituitary-adrenal response to stress. J. Neuroendocrinol. 14 (5), 397-402. https://doi.org/10.1046/j.0007-1331.2002.00790.x.

Meredith, G.E., Callen, S., Scheuer, D.A., 2002. Brain-derived neurotrophic factor expression is increased in the rat amygdala, piriform cortex and hypothalamus following repeated amphetamine administration. Brain Res. 949, 218-227. https://doi org/10.1016/S0006-8993(02)03160-8.

Miczek, K.A., Nikulina, E.M., Shimamoto, A., Covington, H.E., 2011. Escalated or suppressed cocaine reward, tegmental BDNF, and accumbal dopamine caused by episodic versus continuous social stress in rats. J. Neurosci. 31, 9848-9857. https://doi. org/10.1523/JNEUROSCI.0637-11.2011.

Miczek, K.A., Thompson, M.L., Shuster, L., 1982. Opioid-like analgesia in defeated mice. Science 215, 1520-1522. https://doi.org/10.1126/science.7199758.

Montagud-Romero, S., Daza-Losada, M., Vidal-Infer, A., Maldonado, C., Aguilar, M.A., Miñarro, J., Rodríguez-Arias, M., 2014. The novelty-seeking phenotype modulates the long-lasting effects of intermittent ethanol administration during adolescence. PLoS One 9. https://doi.org/10.1371/journal.pone.0092576.

Montagud-Romero, S., Montesinos, J., Pascual, M., Aguilar, M.A., Roger-Sanchez, C., Guerri, C., Miñarro, J., Rodríguez-Arias, M., 2016a. Up-regulation of histone acetylation induced by social defeat mediates the conditioned rewarding effects of cocaine. Prog. Neuro-Psychopharmacol. Biol. Psychiatry 70, 39-48. https://doi.org/10 1016/j.pnpbp.2016.04.016.
Montagud-Romero, S., Nuñez, C., Blanco-Gandia, M.C., Martínez-Laorden, E., Aguilar, M.A., Navarro-Zaragoza, J., Almela, P., Milanés, M.V., Laorden, M.L., Miñarro, J. Rodríguez-Arias, M., 2017. Repeated social defeat and the rewarding effects of cocaine in adult and adolescent mice: dopamine transcription factors, proBDNF signaling pathways, and the TrkB receptor in the mesolimbic system. Psychopharmacology 234, 2063-2075. https://doi.org/10.1007/s00213-0174612-y.

Montagud-Romero, S., Reguilon, M.D., Roger-Sanchez, C., Pascual, M., Aguilar, M.A., Guerri, C., Miñarro, J., Rodríguez-Arias, M., 2016b. Role of dopamine neurotransmission in the long-term effects of repeated social defeat on the conditioned rewarding effects of cocaine. Prog. Neuro-Psychopharmacol. Biol. Psychiatry 311, 864-868. https://doi.org/10.1016/j.pnpbp.2016.07.008.

Nasanbuyan, N., Yoshida, M., Takayanagi, Y., Inutsuka, A., Nishimori, K., Yamanaka, A., Onaka, T., 2018. Oxytocin-oxytocin receptor systems facilitate social defeat posture in male mice. Endocrinology 159, 763-775. https://doi.org/10.1210/en.201700606.

Nestler, E.J., Carlezon, W.A., 2006. The mesolimbic dopamine reward circuit in depression. Biol. Psychiatry 59, 1151-1159. https://doi.org/10.1016/j.biopsych.2005.09. 018.

Neumann, I.D., Slattery, D.A., 2016. Oxytocin in general anxiety and social fear: a translational approach. Biol. Psychiatry 79, 213-221. https://doi.org/10.1016/j. biopsych.2015.06.004.

Neumann, I.D., Wigger, A., Torner, L., Holsboer, F., Landgraf, R., 2000. Brain oxytocin inhibits basal and stress-induced activity of the hypothalamo-pituitary-adrenal axis in male and female rats: partial action within the paraventricular nucleus. J. Neuroendocrinol. 12, 235-243. https://doi.org/10.1046/j.1365-2826.2000.00442.x.

Nikulina, E.M., Johnston, C.E., Wang, J., Hammer, R.P., 2014. Neurotrophins in the ventral tegmental area: role in social stress, mood disorders and drug abuse. Neuroscience 282, 122-138. https://doi.org/10.1016/j.neuroscience.2014.05.028.

Nikulina, E.M., Lacagnina, M.J., Fanous, S., Wang, J., Hammer, R.P., 2012. Intermittent social defeat stress enhances mesocorticolimbic $\triangle$ FosB/BDNF co-expression and persistently activates corticotegmental neurons: implication for vulnerability to psychostimulants. Neuroscience 212, 38-48. https://doi.org/10.1016/j. neuroscience.2012.04.012.

Numan, S., Lane-Ladd, S.B., Zhang, L., Lundgren, K.H., Russell, D.S., Seroogy, K.B., Nestler, E.J., 1998. Differential regulation of neurotrophin and trk receptor mRNAs in catecholaminergic nuclei during chronic opiate treatment and withdrawal. J. Neurosci. 18, 10700-10708. https://doi.org/10.1523/jneurosci.18-24-10700.1998.

Onaka, T., Takayanagi, Y., Yoshida, M., 2012. Roles of oxytocin neurones in the control of stress, energy metabolism, and social behaviour. J. Neuroendocrinol. 24, 587-598. https://doi.org/10.1111/j.1365-2826.2012.02300.x.

Parker, K.J., Buckmaster, C.L., Schatzberg, A.F., Lyons, D.M., 2005. Intranasal oxytocin administration attenuates the ACTH stress response in monkeys. Psychoneuroendocrinology 30, 924-929. https://doi.org/10.1016/j.psyneuen.2005. 04.002.

Pedersen, C.A., Smedley, K.L., Leserman, J., Jarskog, L.F., Rau, S.W., Kampov-Polevoi, A., Casey, R.L., Fender, T., Garbutt, J.C., 2013. Intranasal oxytocin blocks alcohol withdrawal in human subjects. Alcohol Clin. Exp. Res. 37, 484-489. https://doi.org/ 10.1111/j.1530-0277.2012.01958.x.

Peters, S., Slattery, D.A., Uschold-Schmidt, N., Reber, S.O., Neumann, I.D., 2014. Dosedependent effects of chronic central infusion of oxytocin on anxiety, oxytocin receptor binding and stress-related parameters in mice. Psychoneuroendocrinology 42, 225-236. https://doi.org/10.1016/j.psyneuen.2014.01.021.

Petrovic, P., Kalisch, R., Singer, T., Dolan, R.J., 2008. Oxytocin attenuates affective evaluations of conditioned faces and amygdala activity. J. Neurosci. https://doi.org/ 10.1523/JNEUROSCI.4572-07.2008.

Pizarro, J.M., Lumley, L.A., Medina, W., Robison, C.L., Chang, W.E., Alagappan, A., Bah, M.J., Dawood, M.Y., Shah, J.D., Mark, B., Kendall, N., Smith, M.A., Saviolakis, G.A., Meyerhoff, J.L., 2004. Acute social defeat reduces neurotrophin expression in brain cortical and subcortical areas in mice. Brain Res. 1025, 10-20. https://doi.org/10. 1016/j.brainres.2004.06.085.

Purba, J.S., Hoogendijk, W.J.G., Hofman, M.A., Swaab, D.F., 1996. Increased number of vasopressin- and oxytocin-expressing neurons in the paraventricular nucleus of the hypothalamus in depression. Arch. Gen. Psychiatr. 53, 137-143. https://doi.org/10. 1001/archpsyc.1996.01830020055007.

Qi, J., Yang, J.Y., Wang, F., Zhao, Y.N., Song, M., Wu, C.F., 2009. Effects of oxytocin on methamphetamine-induced conditioned place preference and the possible role of glutamatergic neurotransmission in the medial prefrontal cortex of mice in reinstatement. Neuropharmacology 56, 856-865. https://doi.org/10.1016/j. neuropharm.2009.01.010.

Quadros, I.M.H., Miczek, K.A., 2009. Two modes of intense cocaine bingeing: increased persistence after social defeat stress and increased rate of intake due to extended access conditions in rats. Psychopharmacology 206, 109-120. https://doi.org/10. 1007/s00213-009-1584-6.

Reguilón, M.D., Montagud-Romero, S., Ferrer-Pérez, C., Roger-Sánchez, C., Aguilar, M.A., Miñarro, J., Rodríguez-Arias, M., 2017. Dopamine D2receptors mediate the increase in reinstatement of the conditioned rewarding effects of cocaine induced by acute social defeat. Eur. J. Pharmacol. 799, 48-57. https://doi.org/10.1016/j.ejphar.2017. 01.039.

Ring, R.H., Malberg, J.E., Potestio, L., Ping, J., Boikess, S., Luo, B., Schechter, L.E., Rizzo, S., Rahman, Z., Rosenzweig-Lipson, S., 2006. Anxiolytic-like activity of oxytocin in male mice: behavioral and autonomic evidence, therapeutic implications. Psychopharmacology 185, 218-225. https://doi.org/10.1007/s00213-005-0293-z.

Rodríguez-Arias, M., Castillo, A., Daza-Losada, M., Aguilar, M.A., Miñarro, J., 2009. Effects of extended cocaine conditioning in the reinstatement of place preference. Physiol. Behav. 96, 620-630. https://doi.org/10.1016/j.physbeh.2008.12.011. 
Rodríguez-Arias, M., Miñarro, J., Aguilar, M.A., Pinazo, J., Simón, V.M., 1998. Effects of risperidone and SCH 23390 on isolation-induced aggression in male mice. Eur. Neuropsychopharmacol 8, 95-103. https://doi.org/10.1016/S0924-977X(97) 00051-5.

Rodríguez-Arias, M., Montagud-Romero, S., Rubio-Araiz, A., Aguilar, M.A., MartínGarcía, E., Cabrera, R., Maldonado, R., Porcu, F., Colado, M.I., Miñarro, J., 2017. Effects of repeated social defeat on adolescent mice on cocaine-induced CPP and selfadministration in adulthood: integrity of the blood-brain barrier. Addict. Biol. 22, 129-141. https://doi.org/10.1111/adb.12301.

Rodriguez-Arias, M., Navarrete, F., Blanco-Gandia, M.C., Arenas, M.C., Bartoll-Andrés, A., Aguilar, M.A., Rubio, G., Miñarro, J., Manzanares, J., 2016. Social defeat in adolescent mice increases vulnerability to alcohol consumption. Addict. Biol. 21, 87-97. https://doi.org/10.1111/adb.12184.

Sarnyai, Z., Babarczy, E., Kriván, M., Szabó, G., Kovács, G.L., Barth, T., Telegdy, G., 1991. Selective attenuation of cocaine-induced stereotyped behaviour by oxytocin: putative role of basal forebrain target sites. Neuropeptides 19, 51-56. https://doi.org/10. 1016/0143-4179(91)90073-R.

Sarnyai, Z., Kovács, G.L., 1994. Role of oxytocin in the neuroadaptation to drugs of abuse. Psychoneuroendocrinology 19, 85-117. https://doi.org/10.1016/0306-4530(94) 90062-0.

Sarnyai, Z., Kovács, G.L., 2014. Oxytocin in learning and addiction: from early discoveries to the present. Pharmacol. Biochem. Behav. 119, 3-9. https://doi.org/10.1016/j.pbb. 2013.11.019.

Sarnyai, Z., Szabó, G., Kovacs, G.L., Telegdy, G., 1990. Oxytocin attenuates the cocaineinduced exploratory hyperactivity in mice. Neuroreport 1, 200-202. https://doi.org/ 10.1097/00001756-199011000-00006.

Sarnyai, Z., Szabó, G., Kovács, G.L., Telegdy, G., 1992. Opposite actions of oxytocin and vasopressin in the development of cocaine-induced behavioral sensitization in mice. Pharmacol. Biochem. Behav. 43, 491-494. https://doi.org/10.1016/0091-3057(92) 90182-F.

Selten, J.P., Van Der Ven, E., Rutten, B.P.F., Cantor-Graae, E., 2013. The social defeat hypothesis of schizophrenia: an update. Schizophr. Bull. 39, 1180-1186. https://doi. org/10.1093/schbul/sbt134.

Sinha, R., Shaham, Y., Heilig, M., 2011. Translational and reverse translational research on the role of stress in drug craving and relapse. Psychopharmacology 218, 69-82. https://doi.org/10.1007/s00213-011-2263-y.

Slattery, D.A., Neumann, I.D., 2010. Chronic icv oxytocin attenuates the pathologica high anxiety state of selectively bred Wistar rats. Neuropharmacology 58, 56-61. https://doi.org/10.1016/j.neuropharm.2009.06.038.

Smith, A.S., Wang, Z., 2014. Hypothalamic oxytocin mediates social buffering of the stress response. Biol. Psychiatry 1-8. https://doi.org/10.1016/j.biopsych.2013.09. 017.

Soria, G., Barbano, M.F., Maldonado, R., Valverde, O., 2008. A reliable method to study cue-, priming-, and stress-induced reinstatement of cocaine self-administration in mice. Psychopharmacology 199, 593-603. https://doi.org/10.1007/s00213-0081184-X.

Steketee, J.D., Kalivas, P.W., 2011. Drug wanting: behavioral sensitization and relapse to drug-seeking behavior. Pharmacol. Rev. 63, 348-365. https://doi.org/10.1124/pr. 109.001933.

Taylor, S.L., Stanek, L.M., Ressler, K.J., Huhman, K.L., 2011. Differential brain-derived neurotrophic factor expression in limbic brain regions following social defeat of territorial aggression. Behav. Neurosci. 125, 911-920. https://doi.org/10.1037/ a0026172.

Thomas, M.J., Kalivas, P.W., Shaham, Y., 2008. Neuroplasticity in the mesolimbic dopamine system and cocaine addiction. Br. J. Pharmacol. https://doi.org/10.1038/ bjp.2008.77.

Tornatzky, W., Miczek, K.A., 1993. Long-term impairment of autonomic circadian rhythms after brief intermittent social stress. Physiol. Behav. 53, 983-993. https:// doi.org/10.1016/0031-9384(93)90278-N.
Tsai, S.J., 2007. Increased central brain-derived neurotrophic factor activity could be a risk factor for substance abuse: implications for treatment. Med. Hypotheses 68 , 410-414. https://doi.org/10.1016/j.mehy.2006.05.035.

Tsankova, N.M., Berton, O., Renthal, W., Kumar, A., Neve, R.L., Nestler, E.J., 2006. Sustained hippocampal chromatin regulation in a mouse model of depression and antidepressant action. Nat. Neurosci. 9, 519-525. https://doi.org/10.1038/nn1659.

Tzschentke, T.M., 2007. Measuring reward with the conditioned place preference (CPP) paradigm: update of the last decade. Addict. Biol. 12, 227-462. https://doi.org/10. 1111/j.1369-1600.2007.00070.x.

Unternaehrer, E., Luers, P., Mill, J., Dempster, E., Meyer, A.H., Staehli, S., Lieb, R., Hellhammer, D.H., Meinlschmidt, G., 2012. Dynamic changes in DNA methylation of stress-associated genes (OXTR, BDNF) after acute psychosocial stress. Transl. Psychiatry 2. https://doi.org/10.1038/tp.2012.77.

Vidal-Infer, A., Arenas, M.C., Daza-Losada, M., Aguilar, M.A., Miñarro, J., RodríguezArias, M., 2012. High novelty-seeking predicts greater sensitivity to the conditioned rewarding effects of cocaine. Pharmacol. Biochem. Behav. 102, 124-132. https://doi. org/10.1016/j.pbb.2012.03.031.

Waldherr, M., Neumann, I.D., 2007. Centrally released oxytocin mediates mating-induced anxiolysis in male rats. Proc. Natl. Acad. Sci. Unit. States Am. 04, 16681-16684. https://doi.org/10.1073/pnas.0705860104.

Wang, Q., Shao, F., Wang, W., 2018. Region-dependent alterations in cognitive function and ERK1/2 signaling in the PFC in rats after social defeat stress. Neural Plast. 2018. https://doi.org/10.1155/2018/9870985.

Windle, R.J., Shanks, N., Lightman, S.L., Ingram, C.D., 1997. Central oxytocin administration reduces stress-induced corticosterone release and anxiety behavior in rats. Endocrinology 138, 2829-2834. https://doi.org/10.1210/endo.138.7.5255.

Wotjak, C.T., Kubota, M., Liebsch, G., Montkowski, A., Holsboer, F., Neumann, I., Landgraf, R., 1996. Release of vasopressin within the rat paraventricular nucleus in response to emotional stress: a novel mechanism of regulating adrenocorticotropic hormone secretion? J. Neurosci. 16, 7725-7732. https://doi.org/10.1110/ps.8.3. 529.

Xu, H., Wang, J., Zhang, K., Zhao, M., Ellenbroek, B., Shao, F., Wang, W., 2018. Effects of adolescent social stress and antidepressant treatment on cognitive inflexibility and Bdnf epigenetic modifications in the mPFC of adult mice. Psychoneuroendocrinology 88, 92-101. https://doi.org/10.1016/j.psyneuen.2017.11.013.

Yang, B., Ren, Q., Ma, M., Chen, Q.X., Hashimoto, K., 2016a. Antidepressant effects of (+)-MK-801 and (-)-MK-801 in the social defeat stress model. Int. J. Neuropsychopharmacol. 19, 1-5. https://doi.org/10.1093/ijnp/pyw080.

Yang B, Zhang JC, Han M, Yao W, Yang C, Ren Q, Ma M, Chen QX, Hashimoto K. 2016b. Comparison of R-ketamine and rapastinel antidepressant effects in the social defeat stress model of depression. Psychopharmacology. 233, 3647-3657. https://doi.org/ 10.1007/s00213-016-4399-2.

Yap, J.J., Chartoff, E.H., Holly, E.N., Potter, D.N., Carlezon, W.A., Miczek, K.A., 2015 Social defeat stress-induced sensitization and escalated cocaine self-administration: the role of ERK signaling in the rat ventral tegmental area. Psychopharmacology 232, 1555-1569. https://doi.org/10.1007/s00213-014-3796-7.

Yoshida, M., Takayanagi, Y., Inoue, K., Kimura, T., Young, L.J., Onaka, T., Nishimori, K., 2009. Evidence that oxytocin exerts anxiolytic effects via oxytocin receptor expressed in serotonergic neurons in mice. J. Neurosci. 29, 2259-2271. https://doi.org/10. 1523/JNEUROSCI.5593-08.2009.

Zanos, P., Wright, S.R., Georgiou, P., Yoo, J.H., Ledent, C., Hourani, S.M., Kitchen, I. Winsky-Sommerer, R., Bailey, A., 2014. Chronic methamphetamine treatment induces oxytocin receptor up-regulation in the amygdala and hypothalamus via an adenosine A2A receptor-independent mechanism. Pharmacol. Biochem. Behav. 119, 72-79. https://doi.org/10.1016/j.pbb.2013.05.009.

Zhou, L., Sun, W.L., Young, A.B., Lee, K., McGinty, J.F., See, R.E., 2014. Oxytocin reduces cocaine seeking and reverses chronic cocaine-induced changes in glutamate receptor function. Int. J. Neuropsychopharmacol. 18. https://doi.org/10.1093/ijnp/pyu009. 